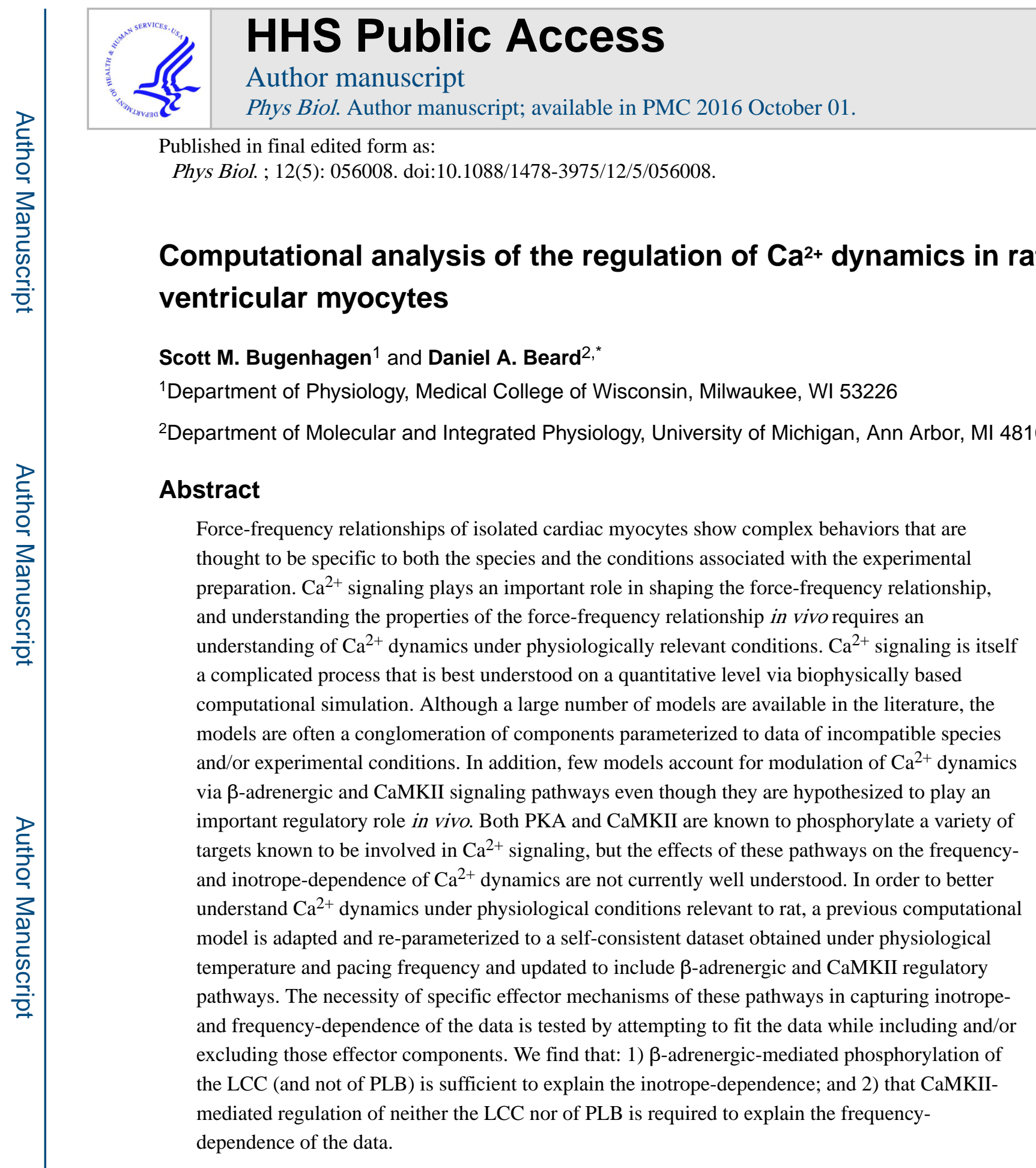

\title{
Introduction
}

The process of excitation-contraction coupling in the heart involves the coordination of electrical signals initiated at the sino-atrial node and mechanical force generation of the myocardium. At the cellular level, this involves transduction of the action potential to

\footnotetext{
*To whom correspondence should be addressed: Department of Molecular and Integrative Physiology, University of Michigan, 2800 Plymouth Rd, Ann Arbor, MI, USA. Tel: 734-763-8040, beardda@umich.edu.

Supporting Citations:

References [63-66] appear in the Supporting Material.
} 
myofibril force generation via an intracellular $\mathrm{Ca}^{2+}$ signaling mechanism. The dynamics associated with $\mathrm{Ca}^{2+}$ signaling are complex, beginning with voltage-mediated trigger flux through sarcolemmal L-type calcium channels (LCCs), resulting in calcium-induced calcium release (CICR) from the sarcoplasmic reticulum (SR) $\mathrm{Ca}^{2+}$ stores via ryanodine receptors (RyRs), and termination following concurrent $\mathrm{Ca}^{2+}$ efflux through the sarcolemma (via the $\mathrm{Na}^{+}-\mathrm{Ca}^{2+}$ exchanger (NCX) and plasma-membrane $\mathrm{Ca}^{2+}$-ATPase (PMCA)) and $\mathrm{Ca}^{2+}$ reuptake into the SR (via the sarcoplasmic-reticulum $\mathrm{Ca}^{2+}$-ATPase (SERCA)). Furthermore, because of the critical role of $\mathrm{Ca}^{2+}$ in determining cardiac contractility, $\mathrm{Ca}^{2+}$ dynamics are heavily regulated by a variety of intrinsic and extrinsic signaling pathways including the intrinsic $\mathrm{Ca}^{2+} /$ calmodulin-dependent protein kinase II (CaMKII) pathway and the extrinsic $\beta$-adrenoreceptor-dependent protein-kinase-A (PKA) pathway.

It is this complexity associated with $\mathrm{Ca}^{2+}$ signaling that makes it difficult to interpret, let alone predict, force-frequency relationships associated with isolated cardiac myocytes. It is perhaps no surprise that the force-frequency relationships reported by different studies are rather heterogeneous, with some reporting positive [1,2], others negative [3,4], and still others reporting biphasic [5,6] force-frequency patterns. Dibb et al. [7] point out that these disparate results are likely the result of both species-specific differences and differences related to the experimental conditions associated with the experimental preparation (for example, temperature and frequency range). To address these disparities and to better understand frequency-dependent behavior in vivo, they carried out a study measuring frequency-dependent $\left[\mathrm{Ca}^{2+}\right]_{\mathrm{i}}$ responses in rat at physiologically relevant temperature and pacing frequencies. In addition, Dibb et al. point out that in vivo changes in heart rate are associated with changes in $\beta$-adrenergic stimulation. To shed light on how such stimulation alters frequency-dependent behavior, they conducted experiments involving a dose of isoprenaline, a non-selective $\beta$-agonist, in their study [7].

Although physiological experiments provide the data necessary to form hypotheses about the mechanisms governing the behavior of a biological system, sometimes even the most carefully designed experiments produce results that are difficult to rationalize as evidenced by the studies cited above. Often, testing and refining hypotheses generated by experimental data is greatly aided by formalizing those hypotheses as quantitative computational models [8]. In fact, great progress has already been made in understanding $\mathrm{Ca}^{2+}$ dynamics in isolated myocytes through the development of biophysically based computational models of $\mathrm{Ca}^{2+}$ transport and buffering in cardiac myocytes [9-13]. However, these models suffer many of the same drawbacks associated with the experimental studies cited above; namely, lack of consistency (species, temperature, etc.) and physiologically irrelevant conditions of experimental data used to parameterize model components. Furthermore, components of these models are heavily recycled and seldom updated to account for more accurate and/or relevant experimental data as it becomes available [14].

Recognizing the limitations associated with these models, Li et al. [15] updated one such model, the Bondarenko et al. model of the mouse ventricular myocyte [16], by reparameterizing model components to fit a more self-consistent dataset obtained at more physiologically relevant experimental conditions. This updated model provided a more reliable means of quantifying the effect of $\mathrm{NCX}$ up-regulation on $\mathrm{Ca}^{2+}$ dynamics and 
electrophysiology in mouse than would have been possible using previously published models. Following Li et al. and in line with the aims of the Virtual Physiological Rat Project [17], the aim of the current study is to similarly update an existing model of $\mathrm{Ca}^{2+}$ dynamics in the rat (the Hinch model [13]) to account for the recent, self-consistent, and physiologically relevant dataset of Dibb et al. [7]. As with the Bondarenko model, the Hinch model was parameterized against heterogeneous data sources under non-ideal experimental conditions (e.g. room temperature and pacing frequencies slower than observed in vivo). In addition, the model did not include a $\beta$-adrenergic regulatory pathway, which is necessary in order to account for those datasets in the Dibb et al. study involving isoprenaline. A $\beta$ adrenergic regulatory component was therefore added in the present work.

The updated model is used here to study both frequency-dependent and inotrope-dependent behaviors of $\mathrm{Ca}^{2+}$ dynamics under physiologically relevant conditions. As discussed above, force-frequency relationships in particular are complex and currently not well understood, involving but not limited to: LCC, RyR, and SERCA kinetics; SR $\mathrm{Ca}^{2+}$ load; intra- and extracellular $\mathrm{Na}^{+}$concentration; cross-bridge kinetics; and signaling via calmodulin and CaMKII [18]. Of the above phenomena, the role of CaMKII is perhaps the most controversial. Thought to be an important frequency detector in both neurons and cardiac myocytes $[19,20]$, CaMKII has been implicated in a myriad of signaling roles in the heart [21]. Potentially important to the force-frequency relationship are its possible roles in RyR leakiness, frequency dependent facilitation of LCCs, and frequency-dependent acceleration of relaxation (FDAR); however each of these roles are currently debated.

There are a number of controversies regarding the role of CaMKII-mediated RyR phosphorylation [58,59]: RyR open probability has been shown to both increase [22] and decrease [23] in the presence of CaMKII; transgenic mouse models have produced conflicting evidence regarding the importance of CaMKII-mediated RyR phosphorylation in force-frequency relationships [60,61]; and a simulation study has shown that, ultimately, RyR phosphorylation plays only a minor role in regulating diastolic RyR flux [24].

Regarding the LCC, although studies have demonstrated a use-dependent facilitation of LCC current attributed to CaMKII phosphorylation [25,26], under more physiological conditions and pacing rates no such facilitation was observed [2,7]. Finally, while CaMKII inhibitors have been shown to suppress FDAR $[27,28,29,61]$ and some studies support a CaMKIImediated phospholamban (PLB) phosphorylation mechanism for FDAR [30,31,61], other studies show no effect of CaMKII inhibitors and have shown that FDAR depends on neither PLB nor SERCA phosphorylation $[5,6,32,33]$. While inotrope-dependent behavior of $\mathrm{Ca}^{2+}$ dynamics is better understood than frequency-dependent behavior (with PKA-mediated LCC and PLB phosphorylation widely regarded as the primary $\mathrm{Ca}^{2+}$-mediated mechanisms for the inotropic and lusitropic effects of $\beta$-adrenergic agonists, respectively), it is also not without controversy; specifically, although PKA-mediated phosphorylation has the potential to alter the opening probability of RyRs, whether this has any functional effect is debatable. (For example, see [34] for discussion.)

In order to better understand the functional importance of these signaling mechanisms towards $\mathrm{Ca}^{2+}$ dynamics, we apply the principle of parsimony known as Occam's razor, which states that the best among competing hypotheses is that which is as simple as possible 
and only as complex as necessary. We use the computational model as a tool to apply the razor by systematically building in the minimal level of complexity (in the form of the signaling components described above) necessary to explain the dataset of Dibb et al. [7]. Our goal is not to determine the correctness of competing theories in the literature, but rather to determine which mechanisms are required to explain the experimental observations of Dibb et al., and thus which mechanisms are functionally most important under the specific set of physiologically relevant experimental conditions associated with the Dibb dataset.

\section{Model Development}

One goal of this study is to update the existing Hinch [13] model of $\mathrm{Ca}^{2+}$ dynamics using the self-consistent and physiologically relevant dataset of Dibb et al. [7]. The Hinch framework is chosen because the default parameter values of the model are based on rat (therefore providing a reliable initial guess and range of constraints for the parameter optimization protocols carried out in the present study) and because it represents a relatively simple local control model of CICR which is able to account for the high-gain, graded SR calcium release response to trigger calcium from LCCs as observed experimentally. One criticism of the Hinch model concerns its phenomenological representation of local release, which does not account for local depletion of junctional $\mathrm{SR} \mathrm{Ca}^{2+}$ and assumes termination of release occurs through $\mathrm{Ca}^{2+}$ dependent inactivation of the RyR (the role of these processes are currently a subject of debate in the literature); these assumptions do not pose a problem for the current analysis however, as the relationships we seek to simulate concern overall flux balance rather than details of RyR gating. However, the published Hinch model does not include either of the CaMKII or $\beta$-adrenergic signaling pathways. Since another goal of this work is to explore the regulatory mechanisms necessary to explain the frequency- and inotrope-dependent observations of the Dibb data, the Hinch model is further updated to include aspects of these two signaling pathways. The components included in the overall model are illustrated in Fig. 1.

\section{B-adrenergic pathway}

Although models of the complete $\beta$-adrenergic signaling pathway exist (e.g. the model of Saucerman et al. [35]), following the general approach of the current study of applying the simplest possible models and adding in complexity only when needed, the full $\beta$-adrenergic signaling cascade is not included in the model. Instead, simple phenomenological models of $\beta$-adrenergic-mediated LCC and PLB phosphorylation which are able to approximate both the steady-state and dynamic isoprenaline dose responses of relevant functional data are applied. The steady-state dose response data used to parameterize the LCC phosphorylation component come from Saraiva et al. [36] and are shown along with model fits in Fig. 2. The data are fit to a Hill equation of form

$$
\bar{\varphi}_{\mathrm{lcc}, \text { iso }}=\frac{\varphi_{\mathrm{lcc}, \text { iso }}^{\max }}{1+\left(K_{\mathrm{lcc}, \text { iso }} /[\text { iso }]\right)^{H_{\mathrm{lcc}, \text { iso }}}}
$$


and are used to obtain estimates of the half-response concentration $K_{\mathrm{lcc} \text {,iso }}$ and Hill coefficient $H_{\mathrm{lcc} \text {,iso }}$ parameters. In Eq. 1, [iso] is the concentration of the isoprenaline dose, and $\bar{\varphi}_{\text {lcc,iso }}$ and $\varphi_{\text {lcc,iso }}^{\max }$ represent the steady-state and maximum fraction of LCCs with PKA phosphorylation site in the phosphorylated state, respectively. It is assumed that $\bar{\varphi}_{\text {lcc,iso }}$ is zero at zero [iso], and $\varphi_{\text {lcc,iso }}^{\max }$ is allowed to be an adjustable parameter in the model. Although the data of Yatani and Brown [37] suggest the presence of both a fast and slow time constant (150 milliseconds and 36 seconds, respectively) in the LCC-isoprenaline response of atrial myocytes from guinea pig, the data of Frace et al. in frog ventricle myocytes show the LCC response to isoprenaline to occur with a few second delay followed by a single long (20 seconds) time constant attributed to the rate limiting-step associated with LCC phosphorylation [62]; here we find that a single slow time constant is sufficient to explain the data of Dibb et al. [7]. Therefore, the dynamics associated with $\beta$-adrenergic mediated LCC phosphorylation are modeled using a first-order process given by

$$
\frac{d \varphi_{\mathrm{lcc}, \text { iso }}}{d t}=\frac{-\varphi_{\mathrm{lcc}, \text { iso }}+\bar{\varphi}_{\mathrm{lcc}, \text { iso }}}{\tau_{\mathrm{lcc}, \text { iso }}}
$$

where time constant $\tau_{\mathrm{lcc}, \text { iso }}$ is an adjustable parameter in the overall model.

The steady-state dose response data used to parameterize the PLB phosphorylation component come from Hagemann et al. [30] and are shown along with model fits in Fig. 3. The data are fit to a Hill equation of form

$$
\bar{\varphi}_{\mathrm{plb}, \text { iso }}=\frac{\varphi_{\mathrm{plb}, \text { iso }}^{\max }}{1+\left(K_{\mathrm{plb}, \text { iso }} /[\text { iso }]\right)^{H_{\mathrm{plb}, \text { iso }}}}
$$

and are used to obtain estimates of the half-response concentration $K_{\text {plb,iso }}$ and Hill coefficient $H_{\text {plb,iso }}$ parameters. In Eq. $3, \bar{\varphi}_{\text {plb,iso }}$ and $\varphi_{\text {plb,iso }}^{\max }$ represent the steady-state and maximum fraction of PLB with PKA phosphorylation site in the phosphorylated state, respectively. It is assumed that $\bar{\varphi}_{\mathrm{plb} \text {,iso }}$ is zero at zero [iso], and $\varphi_{\mathrm{plb} \text {,iso }}^{\max }$ is allowed to be an adjustable parameter in the overall model. We find that the dynamics associated with $\beta$ adrenergic mediated PLB phosphorylation are well approximated as a first order process given by

$$
\frac{d \varphi_{\mathrm{plb}, \text { iso }}}{d t}=\frac{-\varphi_{\mathrm{plb}, \text { iso }}+\bar{\varphi}_{\mathrm{plb}, \text { iso }}}{\tau_{\mathrm{plb}, \text { iso }}} .
$$

A fit of Eq. 4 to the dynamic $\beta$-adrenergic mediated SERCA flux/PLB phosphorylation data of Lindemann et al. [38] and Li et al. [39] is shown, demonstrating that the first order process of Eq. 4 is sufficient to describe the dynamics. However, because the data of 
Lindemann et al. and $\mathrm{Li}$ et al. are from guinea pig and mice, respectively, at nonphysiological temperature, the time constant $\tau_{\text {plb,iso }}$ is allowed to be an adjustable parameter in the overall model. In this study, we do not include a RyR phosphorylation mechanism in our $\beta$-adrenergic model.

\section{CaMKII pathway}

Although a number of models of CaMKII have been previously described [40-43], here the contribution of CaMKII to $\mathrm{Ca}^{2+}$ dynamics is accounted for simply by introducing free parameters $\varphi_{\mathrm{Icc}, \mathrm{CaMK}}, \varphi_{\mathrm{plb}, \mathrm{CaMK}} \in[0,1]$ corresponding to the fraction of phosphorylated CaMKII target site on the LCC and on PLB, respectively. In the calcium dynamics model developed below, $\varphi_{\mathrm{Icc}, \mathrm{CaMK}}$ and $\varphi_{\mathrm{plb}, \mathrm{CaMK}}$ represent freely adjustable additive terms used to account for potential effects of CaMKII on LCC and PLB activity under any particular experimental condition. Thus the values of these parameters are allowed to be adjustable for each experimental condition. As will be shown below, satisfactory fits to the data were achieved with $\varphi_{\text {Icc,CaMK }}$ and $\varphi_{\text {plb,CaMK }}$ set to zero, indicating that accounting for the $\beta$ adrenergic pathway alone is sufficient to explain the data analyzed below.

The rationale is that this approach provides a maximal degree of freedom in fitting the data so that an upper bound for the improvement in fit that could be achieved by adding in a mechanistic model of CaMKII kinetics can be estimated. Since this estimated upper bound (see below) was not significant enough to warrant inclusion of CaMKII dynamics, such a model is not considered here.

\section{CaRU model}

The three-state formulations of the LCC and RyR and nine-state formulation of the CaRU of the Hinch model are adopted here, along with the same rapid-equilibrium assumptions of the channel open/closed states, yielding a baseline CaRU model with four dynamic-states. The nine-state and reduced four-state models are illustrated in Fig. 4. The expressions for the rate constants displayed in the figure (modified slightly from those of Hinch et al. [13] but mathematically equivalent) are below:

$$
\begin{aligned}
& \alpha_{+}=\frac{k_{\text {open }}^{\text {lcc }}}{1+e^{-\frac{V_{\mathrm{m}}-V_{\text {half }}^{\text {Icc }}}{\Delta V_{\text {lcc }}}}} \\
& \alpha_{-}=k_{\text {close,mode1 }}^{\text {lcc }} \text { or } k_{\text {close,mode } 2}^{\text {lcc }} \\
& \varepsilon_{+}\left(\left[\mathrm{Ca}^{2+}\right]_{\mathrm{ds}}\right)=\left[\mathrm{Ca}^{2+}\right]_{\mathrm{ds}}\left(k_{\text {inact,min }}^{\mathrm{lcc}}+\frac{k_{\text {inact,max }}^{\mathrm{lcc}}-k_{\text {inact,min }}^{\mathrm{lcc}}}{1+e^{-\frac{V_{\mathrm{m}}-V_{\text {half }}^{\mathrm{llc}}}{\Delta V_{\text {licc }}}}}\right)
\end{aligned}
$$

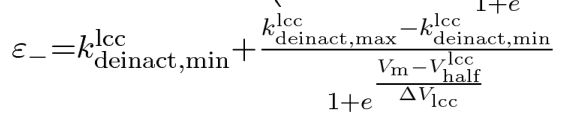




$$
\begin{gathered}
\beta_{+}\left(\left[\mathrm{Ca}^{2+}\right]_{\mathrm{ds}}\right)=\frac{k_{\mathrm{open}}^{\mathrm{ryr}}}{1+\left(K_{\mathrm{ryr} /} /\left[\mathrm{Ca}^{2+}\right]_{\mathrm{ds}}\right)^{2}} \\
\beta_{-}=k_{\text {close }}^{\mathrm{ryr}} \\
\mu_{+}\left(\left[\mathrm{Ca}^{2+}\right]_{\mathrm{ds}}\right)=k_{\text {inact,min }}^{\mathrm{ryr}}+\frac{k_{\text {inact,max }}^{\mathrm{ryr}}-k_{\text {inact,min }}^{\mathrm{ryr}}}{1+\left(K_{\mathrm{ryr}} /\left[\mathrm{Ca}^{2+}\right]_{\mathrm{ds}}\right)^{2}} \\
\mu_{-}\left(\left[\mathrm{Ca}^{2+}\right]_{\mathrm{ds}}\right)=k_{\text {deinact,max }}^{\mathrm{ryr}}-\frac{k_{\text {deinact,max }}^{\mathrm{ryr}}-k_{\mathrm{deinact}, \text { min }}^{\mathrm{ry}}}{1+\left(K_{\mathrm{ryr}} /\left[\mathrm{Ca}^{2+}\right]_{\mathrm{ds}}\right)^{2}}
\end{gathered}
$$

Where Eq. 5 represents the transition rates associated with the LCC and Eq. 6 represents those associated with the RyR.

Unlike the study of Hinch et al. [13], here we account for regulation of the LCC by CaMKII and $\beta$-adrenergic signaling pathways via phosphorylation of the channel. Both CaMKII and $\beta$-adrenergic stimulation of the LCC have been shown to shift the gating pattern of the channel from a low activity mode, characterized by brief infrequent channel openings, to a high activity mode, characterized by more frequent, longer lasting channel openings [44,45]. As the actual phosphorylation targets of CaMKII and PKA are currently unresolved [46], we assume that they act on independent sites, each capable of shifting the channel from a low (mode 1) to a high (mode 2) activity mode. To account for these two modes, $a_{-}$in Eq. 5 assumes one of two possible values depending on whether the LCC is operating in mode 1 or 2 . The fraction of channels operating in mode 2 is given by

$$
\varphi_{\mathrm{lcc}}=\varphi_{\mathrm{lcc}, \mathrm{CaMK}}+\varphi_{\mathrm{lcc}, \text { iso }}-\varphi_{\mathrm{lcc}, \mathrm{CaMK}} \varphi_{\mathrm{lcc}, \text { iso }}
$$

where $\varphi_{\mathrm{lcc}, \mathrm{CaMK}}$ and $\varphi_{\mathrm{lcc}, \text { iso }}$ are defined above.

Hinch et al. [13] assume that $\left[\mathrm{Ca}^{2+}\right]$ in the diad space reaches steady-state on a time scale much faster than LCC and RyR channel opening/closing; therefore, $\left[\mathrm{Ca}^{2+}\right]_{\mathrm{ds}}$ takes on four possible values, denoted in Fig. 4 by $c_{i, j}$ where $i \in\{\mathrm{O}, \mathrm{C}\}$ and $j \in\{\mathrm{O}, \mathrm{C}\}$ represent the open/ closed state of the LCC and RyR, respectively (both closed and inactivated channels are in the closed, or $\mathrm{C}$, state), depending on the state of the CaRU. Expressions for the $c_{i, j}$ are obtained by solving

$$
J_{\mathrm{lcc}}^{i, j}+J_{\mathrm{ryr}}^{i, j}-J_{\mathrm{ds}}^{i, j}=0
$$

for $c_{i, j}$, where 


$$
\begin{gathered}
J_{\text {lcc }}^{i, j}=\left\{\begin{array}{c}
0 \text { for } i=\mathrm{C}, \text { else } \\
\frac{v_{\mathrm{lcc}} \cdot V_{\mathrm{m}} \frac{2 F}{R T}\left(\left[\mathrm{Ca}^{2+}\right]_{\mathrm{o}} e^{-V_{\mathrm{m}} \frac{2 F}{R T}}-c_{\mathrm{O}, j}\right)}{1-e^{-V_{\mathrm{m}} \frac{2 F}{R T}}}
\end{array}\right. \\
J_{\mathrm{ryr}}^{i, j}=\left\{\begin{array}{c}
0 \text { for } j=\mathrm{C}, \text { else } \\
v_{\mathrm{ryr}}\left(\left[\mathrm{Ca}^{2+}\right]_{\mathrm{sr}}-c_{i, \mathrm{O}}\right)
\end{array}\right. \\
J_{\mathrm{ds}}^{i, j}=v_{\mathrm{ds}}\left(c_{i, j}-\left[\mathrm{Ca}^{2+}\right]_{\mathrm{i}}\right),
\end{gathered}
$$

and are given by

$$
\begin{gathered}
c_{\mathrm{C}, \mathrm{C}}=\left[\mathrm{Ca}^{2+}\right]_{\dot{\mathrm{r}}} \\
c_{\mathrm{C}, \mathrm{O}}=\frac{v_{\mathrm{ds}}\left[\mathrm{Ca}^{2+}\right]_{\mathrm{i}}+v_{\mathrm{ryr}}\left[\mathrm{Ca}^{2+}\right]_{\mathrm{sr}}}{v_{\mathrm{ds}}+v_{\mathrm{ryr}}} \\
c_{\mathrm{O}, \mathrm{C}}=\frac{v_{\mathrm{ds}}\left[\mathrm{Ca}^{2+}\right]_{\mathrm{i}}+v_{\mathrm{lcc}} \cdot V_{\mathrm{m}} \frac{2 F}{R T}\left[\mathrm{Ca}^{2+}\right]_{\mathrm{o}} /\left(e^{V_{\mathrm{m}} \frac{2 F}{R T}}-1\right)}{v_{\mathrm{ds}}+v_{\mathrm{lcc}} \cdot V_{\mathrm{m}} \frac{2 F}{R T} /\left(1-e^{-V_{\mathrm{m}} \frac{2 F}{R T}}\right)} \\
c_{\mathrm{O}, \mathrm{O}}=\frac{v_{\mathrm{ds}}\left[\mathrm{Ca}^{2+}\right]_{\mathrm{i}}+v_{\mathrm{lcc}} \cdot V_{\mathrm{m}} \frac{2 F}{R T}\left[\mathrm{Ca}^{2+}\right]_{\mathrm{o}} /\left(e^{V_{\mathrm{m}} \frac{2 F}{R T}}-1\right)+v_{\mathrm{ryr}}\left[\mathrm{Ca}^{2+}\right]_{\mathrm{sr}}}{v_{\mathrm{ds}}+v_{\mathrm{lcc}} \cdot V_{\mathrm{m}} \frac{2 F}{R T} /\left(1-e^{-V_{\mathrm{m}} \frac{2 F}{R T}}\right)+v_{\mathrm{ryr}}} .
\end{gathered}
$$

Additionally, Hinch et al. [13] assume that channel opening/closing occurs on a timescale much faster than channel inactivation/de-inactivation, allowing for a rapid-equilibrium approximation of the boxed states shown in Fig. 4A and an associated reduction in the number of dynamic states in the model. The rate constants associated with the reduced model (shown in Fig. 4B) are given by:

$$
\begin{gathered}
r_{1, \text { mode } 1}=P\left(y_{\mathrm{OC}} \mid Z_{1}\right) \mu_{+}\left(c_{\mathrm{OC}}\right)+P\left(y_{\mathrm{CC}} \mid Z_{1}\right) \mu_{+}\left(c_{\mathrm{CC}}\right) \\
r_{1, \text { mode } 2}=P\left(y_{\mathrm{OC}} \mid Z_{5}\right) \mu_{+}\left(c_{\mathrm{OC}}\right)+P\left(y_{\mathrm{CC}} \mid Z_{5}\right) \mu_{+}\left(c_{\mathrm{CC}}\right) \\
r_{2, \text { mode } 1}=P\left(y_{\mathrm{OI}} \mid Z_{2}\right) \mu_{-}\left(c_{\mathrm{OC}}\right)+P\left(y_{\mathrm{CI}} \mid Z_{2}\right) \mu_{-}\left(c_{\mathrm{CC}}\right) \\
r_{2, \text { mode } 2}=P\left(y_{\mathrm{OI}} \mid Z_{6}\right) \mu_{-}\left(c_{\mathrm{OC}}\right)+P\left(y_{\mathrm{CI}} \mid Z_{6}\right) \mu_{-}\left(c_{\mathrm{CC}}\right) \\
r_{3}=P\left(y_{\mathrm{IC}} \mid Z_{3}\right) \mu_{+}\left(c_{\mathrm{CC}}\right) \\
r_{4}=\mu_{-}\left(c_{\mathrm{CC}}\right) \\
r_{5, \text { mode } 1}=P\left(y_{\mathrm{CC}} \mid Z_{1}\right) \varepsilon_{+}\left(c_{\mathrm{CC}}\right)+P\left(y_{\mathrm{CO}} \mid Z_{1}\right) \varepsilon_{+}\left(c_{\mathrm{CO}}\right) \\
r_{5, \text { mode } 2=}=P\left(y_{\mathrm{CC}} \mid Z_{5}\right) \varepsilon_{+}\left(c_{\mathrm{CC}}\right)+P\left(y_{\mathrm{CO}} \mid Z_{5}\right) \varepsilon_{+}\left(c_{\mathrm{CO}}\right) \\
r_{6}, r_{8}=\varepsilon_{-} \\
r_{7, \text { mode } 1}=P\left(y_{\mathrm{CI}} \mid Z_{2}\right) \varepsilon_{+}\left(c_{\mathrm{CC}}\right) \\
r_{7, \text { mode } 2}=P\left(y_{\mathrm{CI}} \mid Z_{6}\right) \varepsilon_{+}\left(c_{\mathrm{CC}}\right)
\end{gathered}
$$

Expressions for the conditional probabilities $P\left(y_{i, j} \mid Z_{x}\right)$ in Eq. 11 are given by the steadystate solution of the subsystems corresponding to the boxes drawn in Fig. 4A (the expressions are complex and can be found in the Supporting Material code). The total CaRU fluxes corresponding to the summed flux through all CaRUs in the cell are given by 


$$
\begin{gathered}
J_{\mathrm{lcc}}^{\mathrm{T}}=P(i=\mathrm{O}, j \in\{\mathrm{C}, \mathrm{I}\}) J_{\mathrm{lcc}}^{\mathrm{O}, \mathrm{C}}+P(i=\mathrm{O}, j=\mathrm{O}) J_{\mathrm{lcc}}^{\mathrm{O}, \mathrm{O}} \\
J_{\mathrm{ryr}}^{\mathrm{T}}=P(i \in\{\mathrm{C}, \mathrm{I}\}, j=\mathrm{O}) J_{\mathrm{ryr}}^{\mathrm{C}, \mathrm{O}}+P(i=\mathrm{O}, j=\mathrm{O}) J_{\mathrm{ryr}}^{\mathrm{O}, \mathrm{O}} \\
J_{\mathrm{ds}}^{\mathrm{T}}=P(i \in\{\mathrm{C}, \mathrm{I}\}, j=\mathrm{O}) J_{\mathrm{ds}}^{\mathrm{C}, \mathrm{O}}+P(i=\mathrm{O}, j \in\{\mathrm{C}, \mathrm{I}\}) J_{\mathrm{ds}}^{\mathrm{O}, \mathrm{C}}+P(i=\mathrm{O}, j=\mathrm{O}) J_{\mathrm{ds}}^{\mathrm{O}, \mathrm{O}}
\end{gathered}
$$

where

$$
\begin{gathered}
P(i \in\{\mathrm{C}, \mathrm{I}\}, j=\mathrm{O})=\left(1-\varphi_{\mathrm{lcc}}\right)\left(P\left(y_{\mathrm{CO}} \mid Z_{1}\right) Z_{1}+P\left(y_{\mathrm{IO}} \mid Z_{3}\right) Z_{3}\right)+\varphi_{\mathrm{lcc}}\left(P\left(y_{\mathrm{CO}} \mid Z_{5}\right) Z_{5}+P\left(y_{\mathrm{IO}} \mid Z_{3}\right) Z_{7}\right) \\
P(i=O, \in\{\mathrm{C}, \mathrm{I}\})=\left(1-\varphi_{\mathrm{lcc}}\right)\left(P\left(y_{\mathrm{OC}} \mid Z_{1}\right) Z_{1}+P\left(y_{\mathrm{OI}} \mid Z_{2}\right) Z_{2}\right)+\varphi_{\mathrm{lcc}}\left(P\left(y_{\mathrm{OC}} \mid Z_{5}\right) Z_{5}+P\left(y_{\mathrm{OI}} \mid Z_{6}\right) Z_{6}\right) \\
P(i=\mathrm{O}, j=\mathrm{O})=\left(1-\varphi_{\mathrm{lcc}}\right) P\left(y_{\mathrm{oo}} \mid Z_{1}\right) Z_{1}+\varphi_{\mathrm{lcc}} P\left(y_{\mathrm{Oo}} \mid Z_{5}\right) Z_{5}
\end{gathered}
$$

are the probabilities associated with the corresponding CaRU state. Here it is assumed that LCC phosphorylation/de-phosphorylation occurs on a time scale slower than inactivation/deinactivation of LCCs and RyRs such that the states $Z_{1}-Z_{4}$ are decoupled from states $Z_{5}-Z_{8}$. Thus, the evolution equations of states $Z_{1}-Z_{8}$ are given by:

$$
\begin{aligned}
\frac{d Z_{1}}{d t}= & \left(r_{1, \text { mode } 1}+r_{5, \text { mode } 1}\right) Z_{1}+r_{2, \text { mode } 1} Z_{2}+r_{6} Z_{3} \\
\frac{d Z_{2}}{d t}= & r_{1, \text { model } 1} Z_{1}-\left(r_{2, \text { mode } 1}+r_{7, \text { model }}\right) Z_{2}+r_{8} Z_{4} \\
& \frac{d Z_{3}}{d t}=r_{5, \text { mode } 1} Z_{1}-\left(r_{6}+r_{3}\right) Z_{3}+r_{4} Z_{4} \\
\frac{d Z_{5}}{d t}=- & \left(r_{1, \text { mode2 } 2}+r_{5, \text { mode } 2}\right) Z_{5}+r_{2, \text { mode } 2} Z_{6}+r_{6} Z_{7} \\
\frac{d Z_{6}}{d t}= & r_{1, \text { mode } 2} Z_{5}-\left(r_{2, \text { mode2 } 2}+r_{7, \text { mode } 2}\right) Z_{6}+r_{8} Z_{8} \\
& \frac{d Z_{7}}{d t}=r_{5, \text { mode } 2} Z_{5}-\left(r_{6}+r_{3}\right) Z_{7}+r_{4} Z_{8}
\end{aligned}
$$

where, by conservation of probability,

$$
\begin{gathered}
Z_{4}=1-Z_{1}-Z_{2}-Z_{3}, \text { and } \\
Z_{8}=1-Z_{5}-Z_{6}-Z_{7} .
\end{gathered}
$$

\section{SERCA model}

As with the CaRU, the SERCA model used by Hinch et al. [13] does not account for regulation by CaMKII or $\beta$-adrenergic signaling pathways. SERCA is believed to be endogenously inhibited by PLB, and phosphorylation-mediated disinhibition of PLB has been shown to result in upregulation of SERCA activity, primarily by increasing the apparent affinity of the pump for $\mathrm{Ca}^{2+}$ (i.e. decreasing its $K_{\mathrm{Ca}}$ value) with little to no effect on its maximal velocity [47]. Both CaMKII and PKA are known to have phosphorylation targets on PLB, and the work of Hagemann et al. [48] support the hypothesis that CaMKII and PKA phosphorylation sites independently contribute to PLB-disinhibition mediated 
SERCA upregulation. Here, we modify the expression for SERCA flux used in the Hinch model to account for these observations. The modified expression is given by

$$
J_{\text {serca }}=J_{\text {serca, } \max }\left(\frac{1-\varphi_{\mathrm{plb}}}{1+\left(\zeta_{\mathrm{plb}} K_{\text {serca }} /\left[\mathrm{Ca}^{2+}\right]_{\mathrm{i}}\right)^{2}}+\frac{\varphi_{\mathrm{plb}}}{1+\left(K_{\text {serca }} /\left[\mathrm{Ca}^{2+}\right]_{\mathrm{i}}\right)^{2}}\right)
$$

where $\zeta_{\mathrm{plb}}$ is a factor accounting for PLB-mediated inhibition of SERCA and $\varphi_{\mathrm{plb}}$ is the fraction of PLB in the phosphorylated state, given by

$$
\varphi_{\mathrm{plb}}=\varphi_{\mathrm{plb}, \mathrm{CaMK}}+\varphi_{\mathrm{plb}, \mathrm{iso}}-\varphi_{\mathrm{plb}, \mathrm{CaMK}} \varphi_{\mathrm{plb}, \mathrm{iso}}
$$

where $\varphi_{\mathrm{plb}, \mathrm{CaMK}}$ and $\varphi_{\mathrm{plb} \text {,iso }}$ are defined above.

\section{Whole cell $\mathrm{Ca}^{2+}$ regulation}

As in the Hinch model [13], expressions for the remaining $\mathrm{Ca}^{2+}$ fluxes come directly from Jafri et al. [9]. The NCX flux is given by

$$
J_{\mathrm{ncx}}=-J_{\mathrm{ncx}, \mathrm{o}} \frac{e^{\frac{\eta_{\mathrm{ncx}} V_{\mathrm{m}} F}{R T}}\left[\mathrm{Na}^{+}\right]_{\mathrm{i}}^{3}\left[\mathrm{Ca}^{2+}\right]_{\mathrm{o}}-e^{\frac{\left(\eta_{\mathrm{ncx}}-1\right) V_{\mathrm{m} F}}{R T}}\left[\mathrm{Na}^{+}\right]_{\mathrm{o}}^{3}\left[\mathrm{Ca}^{2+}\right]_{\mathrm{i}}}{\left(K_{\mathrm{ncx}, \mathrm{Na}}^{3}+\left[\mathrm{Na}^{+}\right]_{\mathrm{o}}^{3}\right)\left(K_{\mathrm{ncx}, \mathrm{Ca}}+\left[\mathrm{Ca}^{2+}\right]_{\mathrm{o}}\right)\left(1+k_{\mathrm{ncx}, \mathrm{sat}} e^{\frac{\left(\eta_{\mathrm{ncx}}-1\right) V_{\mathrm{m}} F}{R T}}\right)} .
$$

PMCA flux is given by

$$
J_{\text {pmca }}=\frac{J_{\text {pmca,max }}}{1+\left(K_{\text {pmca }} /\left[\mathrm{Ca}^{2+}\right]_{\mathrm{i}}\right)} \text {. }
$$

SR and sarcolemmal leak currents are given by

$$
J_{\text {leak }, \mathrm{sr}}=v_{\text {leak }, \mathrm{sr}}\left(\left[\mathrm{Ca}^{2+}\right]_{\mathrm{sr}}-\left[\mathrm{Ca}^{2+}\right]_{\mathrm{i}}\right)
$$

and

$$
J_{\text {leak,pm }}=g_{\text {leak,pm }}\left(E_{\mathrm{Ca}}-V_{\mathrm{m}}\right)
$$


respectively, where $E_{\mathrm{Ca}}=R T / 2 / F \log \left(\left[\mathrm{Ca}^{2+}\right]_{\mathrm{o}} /\left[\mathrm{Ca}^{2}+\right]_{\mathrm{i}}\right)$ is the Nernst potential associated with the sarcolemmal $\left[\mathrm{Ca}^{2+}\right]$ gradient.

However, $\mathrm{Ca}^{2+}$ buffering is handled slightly differently than in the Hinch model. Here, the rapid buffering approximation of Trafford et al. [49] (shown to be sufficient to account for the buffering power of the cytosol) including the effects of the fluorophore (Fluo-3 AM) used in the study of Dibb et al. is used to handle buffering in the cytosolic compartment, and is given by

$$
\beta_{\mathrm{i}}=1+\frac{[\mathrm{B}]_{\mathrm{i}} K_{\mathrm{B}, \mathrm{i}}}{\left(K_{\mathrm{B}, \mathrm{i}}+\left[\mathrm{Ca}^{2+}\right]_{\mathrm{i}}\right)^{2}}+\frac{\left[\text { fluo }_{\mathrm{i}} K_{\text {fluo }}\right.}{\left(K_{\text {fluo }}+\left[\mathrm{Ca}^{2+}\right]_{\mathrm{i}}\right)^{2}}
$$

where $[\mathrm{B}]_{\mathrm{i}}$ and [fluo $]_{\mathrm{i}}$ are the concentrations and $K_{\mathrm{B}, \mathrm{i}}$ and $K_{\text {fluo }}$ the dissociation constants of the intrinsic cytosolic buffer and the fluorophore, respectively. In addition, the Hinch model did not include a buffering effect in the SR which is necessary in order to fit the $\mathrm{SR} \mathrm{Ca}^{2+}$ content data of Dibb et al. [7]. Here, as in the cytosolic compartment, we apply a rapid buffering approximation in the SR given by

$$
\beta_{\mathrm{SR}}=1+\frac{[\mathrm{B}]_{\mathrm{SR}} K_{\mathrm{B}, \mathrm{SR}}}{\left(K_{\mathrm{B}, \mathrm{SR}}+\left[\mathrm{Ca}^{2+}\right]_{\mathrm{SR}}\right)^{2}}
$$

where $[\mathrm{B}]_{\mathrm{SR}}$ and $K_{\mathrm{B}, \mathrm{SR}}$ represent the concentration and dissociation constant associated with the intrinsic buffer localized to the SR, respectively.

The $\mathrm{Ca}^{2+}$ flux balance equations for the cytosolic and SR compartments are given by

$$
\begin{aligned}
\frac{d\left[\mathrm{Ca}^{2+}\right]_{i}}{d t}=\frac{J_{\mathrm{ds}}^{\mathrm{T}}+J_{\text {leak }, \mathrm{pm}}+J_{\text {leak }, \mathrm{SR}}-J_{\mathrm{ncx}}-J_{\mathrm{pmca}}-J_{\text {serca }}}{\beta_{\mathrm{i}} \lambda_{\mathrm{i}}} \\
\frac{d\left[\mathrm{Ca}^{2+}\right]_{\mathrm{SR}}}{d t}=\frac{J_{\mathrm{serca}}-J_{\mathrm{ryr}}-J_{\text {leak }, \mathrm{SR}}}{\beta_{\mathrm{SR}} \lambda_{\mathrm{SR}}}
\end{aligned}
$$

where $\lambda_{\mathrm{i}}$ and $\lambda_{\mathrm{SR}}$ represent the volume ratios of the cytosolic and SR compartments relative to total cell volume. Values for $\lambda_{\mathrm{i}}$ and $\lambda_{\mathrm{SR}}$ are taken directly from measurements of Page et al. [50].

\section{Electrophysiology}

Currently, no suitable model of the electrophysiology of rat ventricular myocytes exists. The only model of the rat action potential available in the literature is that of Pandit et al. [51,52], but this model was parameterized to data at room temperature and is unable to simulate action potentials in the range of pacing frequencies observed physiologically in rat (4-10 $\mathrm{Hz}$ ). In addition, this model does not include $\beta$-adrenergic regulation of the action potential. 
Rather than adjusting the Pandit model and modifying it to include $\beta$-adrenergic regulation, we choose a simpler data-driven approach that allows us to account for electrophysiological effects while introducing the fewest possible additional assumptions into the model (see section titled "Electrophysiology Module" in the Supporting Material). The data-driven model consists of a set of phenomenological functions which are able to capture the overall shape and adaptation kinetics of the action potential at different levels of $\beta$-adrenergic stimulation and stimulation frequency but which do not account for the individual currents comprising the action potential as is done in more detailed Hodgkin-Huxley type models. The overall electrophysiology model is fit to the action potential data of Dibb et al. [7] independently from the $\mathrm{Ca}^{2+}$ data, and the electrophysiology model serves as a driving function for the $\mathrm{Ca}^{2+}$ dynamics model.

\section{Methods}

The electrophysiology model (described in the Supporting Material) was fit to action potentials recorded by Dibb et al. [7] under current clamp at 4, 6, and $8 \mathrm{~Hz}$ pacing frequencies in the presence and absence of a $30 \mathrm{nM}$ isoprenaline dose. In order to fit the data, parameters of the model were estimated using MATLAB's fminsearch routine, an implementation of an unconstrained derivative-free simplex search method.

Using the parameterized electrophysiology model as an input, the overall $\mathrm{Ca}^{2+}$ dynamics model is fit to the $\left[\mathrm{Ca}^{2+}\right]_{\mathrm{i}}$ and SR Ca${ }^{2+}$ content data of Dibb et al. [7] obtained in the same experiments as the action potential data under current clamp at 4, 6, and $8 \mathrm{~Hz}$ pacing frequencies in the presence and absence of $30 \mathrm{nM}$ isoprenaline. Calcium dynamics are simulated by solving the system of ODEs associated with the model using MATLAB's ode15s, a variable order solver based on the numerical differentiation formulas. Simulations are performed according to the protocol applied in the study of Dibb et al. [7]. First, the model was simulated from arbitrary initial conditions in the absence of isoprenaline by trains of action potentials at $4 \mathrm{~Hz}$ until a steady-state was reached. Once a steady-state is reached, the pacing frequency is increased to $6 \mathrm{~Hz}$ and simulated until a new steady-state is reached. This procedure was repeated to obtain steady-state $\mathrm{Ca}^{2+}$ transient predictions under each of the experimental conditions. In order to simulate the caffeine experiments used in the study of Dibb et al. [7] to measure SR $\mathrm{Ca}^{2+}$ content, the model was simulated to steady-state, and once reached, membrane potential was clamped at $-80 \mathrm{mV}$, and the SR leak parameter $V_{\text {leak,sr }}$ was increased by a factor of $10^{4}$ in order to simulate the effect of caffeine. SR $\mathrm{Ca}^{2+}$ content was then computed according to the method used by Dibb et al. [7] and described by Varro et al. [53]. Briefly, the increase in NCX current induced by caffeine is multiplied by a correction factor to account for $\mathrm{Ca}^{2+}$ removal by non-electrogenic mechanisms and then integrated to obtain a value for $\mathrm{SR} \mathrm{Ca}^{2+}$ content.

In order to fit the data, we consider the possibility of several different versions of the $\mathrm{Ca}^{2+}$ dynamics model by including or not including $\beta$-adrenergic- and/or CaMKII-dependent LCC and PLB phosphorylation modules into the model. A particular component is excluded from the analysis by setting the associated phosphorylation fraction of that component (i.e. $\varphi_{\text {lcc,iso }}, \varphi_{\text {lcc,CaMKII }}, \varphi_{\text {plb,iso }}$, or $\left.\varphi_{\text {plb,CaMKII }}\right)$ to zero. The model was fit to all datasets simultaneously using a genetic algorithm and least squares objective criterion given by the 
sum of the coefficient of variation of the root-mean-square error associated with each dataset, computed as

$$
\text { scvrmse }=\sum_{i=1}^{N} \frac{1}{\bar{y}_{\text {data }, i}} \sqrt{\frac{\sum_{j=1}^{n_{i}}\left(y_{\text {mode } 1, i}\left(x_{j}\right)-y_{\text {data }, i}\left(x_{j}\right)\right)^{2}}{n_{i}}}
$$

where $N$ is the number of datasets, $n_{i}$ the number of datapoints associated with dataset $i$, $y_{\text {model }}$ is the model predicted and $y_{\text {data }}$ the observed value associated with experimental condition $x_{j}$, and $\bar{y}_{\text {data, } i}$ the mean of the observed values associated with dataset $i$. The datasets consist of panels B-E of Fig. 5 and panels B-C of Fig 6. According to the definition of the scvrmse given by Eq. 25, each dataset is normalized to the number of data points and the mean data value such that the contribution of each dataset to scvrmse is weighted equally. This is important since many more data points are required to capture the $\mathrm{Ca}^{+}$ transient shape data as compared to, for example, SR $\mathrm{Ca}^{2+}$ content data.

Parameters that were adjusted to fit the data are listed as such in Table 1. Initial guesses for all parameter values were either obtained directly from the literature or by fitting model components to other data sources as described above. Parameters were generally constrained to lie within an order of magnitude of the initial guesses during the parameter estimation routine. Because of the several nonlinear interactions between various components in the model, gradient-based search methods could not be used. Such methods generally fail when applied to optimization problems involving non-smooth non-convex parameter landscapes. We have instead applied a MATLAB implementation of a genetic algorithm based on PIKAIA [54] to fit the data. PIKAIA is an adaptive genetic algorithm employing decimalencoding, crossover, elitism, fitness-based roulette-wheel selection, and an adaptive mutation rate. All optimizations of the overall $\mathrm{Ca}^{2+}$ dynamics model were performed using our implementation of PIKAIA on a 64 node computational cluster.

In order to quantitatively compare the relative quality of the models tested in terms of goodness-of-fit and complexity, an Akaike information criterion (AIC) value is computed for each model. The AIC provides a metric to compare the statistical appropriateness of competing models in terms of trade-offs between goodness of fit and number of adjustable parameters. The AIC value of a model is given by

$$
\mathrm{AIC}=2 k-2 \ln (L)
$$

where $k$ represents the number of parameters and $L$ represents the maximized value of the likelihood function of the model. Assuming residuals are normally distributed and independent, the value of AIC can be simplified to 


$$
\mathrm{AIC}=2 k+\sum_{i=1}^{n} \frac{\left(y_{\text {mode } 1, i}-y_{\text {data }, i}\right)^{2}}{\hat{\sigma}_{i}^{2}}
$$

where $n$ is the number of data points, $y_{\text {model, } i}$ represents the optimized model predicted and $y_{\text {data, } i}$ the observed mean value associated with data point $i$, and where $\sigma_{i}^{2}$ represents the estimated variance of observations associated with data point $i$. Here, the values of $\sigma_{i}^{2}$ are computed from the standard error values reported for the associated data points. Data points associated with the normalized $\mathrm{Ca}^{2+}$ transient datasets were excluded from Eq. 27 since no standard errors or confidence intervals were reported for these datasets in the Dibb et al. [7] study and their values are unknown.

Among a set of models, the "best" model (i.e. the one which minimizes the information loss in representing the data using the model) is the one with the lowest value of AIC. The fractional probability that a model A minimizes the information loss relative to a model $\mathrm{B}$ is given by

$$
P_{\text {rel }}=\frac{P(\text { model } \mathrm{A} \text { is best })}{P(\text { model } \mathrm{B} \text { is best })}=e^{\frac{\mathrm{AIC}_{\mathrm{B}}-\mathrm{AIC}_{\mathrm{A}}}{2}}
$$

\section{Results}

\section{Electrophysiology}

Parameter values and model fits associated with the optimal fit of the electrophysiology model to the action potential data of Dibb et al. [7] are shown in the Supporting Material (see Table S1 and Fig S2, respectively). A notable feature in the data is the enhanced frequency sensitivity of the action potential in the presence of isoprenaline. In the model, a good fit was achieved assuming the action potential to be insensitive to changes in frequency without the presence of isoprenaline (although in the data there appears to be some minor changes in the shape of the action potential with frequency). The major effects of isoprenaline on the action potential are enhanced frequency sensitivity and increased duration of the action potential plateau (characterized as an increased value of the $\eta$ parameter of the model). In the model, the relationship between frequency and changes in APD were assumed to be linear. This assumption appears to approximate the behavior of the data well enough, although it is possible that a better fit could be achieved by using a nonlinear (perhaps a polynomial or hyperbolic) relationship between frequency and APD, but requiring more parameters. In any case, the model is able to achieve a satisfactory fit to the data as is using a relatively small number of parameters while accounting for the dynamics associated with action potential adaptation in response to both frequency and isoprenaline. 


\section{$\mathrm{Ca}^{2+}$ dynamics}

Parameter values associated with the optimal fit of the $\mathrm{Ca}^{2+}$ dynamics model to the data are given in Table 1 for the case involving $\beta$-adrenergic phosphorylation of the LCC only, and the associated model fits are shown in Figs. 5 and 6. Fig. 5 shows the current clamp data and Fig. 6 shows the caffeine experiment simulation used to estimate $\mathrm{SR} \mathrm{Ca}^{2+}$ content under the $4 \mathrm{~Hz}$ condition without isoprenaline. The fits show good agreement between simulated and experimentally observed $\left[\mathrm{Ca}^{2+}\right]_{\mathrm{i}}$-frequency and $\left[\mathrm{Ca}^{2+}\right]_{\mathrm{i}}$-isoprenaline relationships as well as $\mathrm{SR} \mathrm{Ca}^{2+}$ content frequency- and isoprenaline-dependent relationships. The model also shows good agreement with $\mathrm{Ca}^{2+}$ transient dynamics, particularly in the baseline (no isoprenaline) case. Agreement with model and data is not quite as good in the isoprenaline case; the reasons for this are not clear, but some possibilities include altered buffering properties of the cell or altered kinetics of the indicator with isoprenaline stimulation. It is interesting to note that the frequency-dependent acceleration of relaxation observed in the data was closely matched even though CaMKII was excluded and no parameters of the SERCA model were dependent on frequency. Also, model simulated diastolic $\mathrm{Ca}^{2+}$ and SR $\mathrm{Ca}^{2+}$ closely matched the data under all conditions, but the model seemed to underpredict and overpredict the increase in $\mathrm{Ca}^{2+}$ transient amplitude at $6 \mathrm{~Hz}$ in the control and isoprenaline stimulated cases, respectively. Finally, the dynamics associated with isoprenaline simulation are well captured using simple first-order kinetics. However, the time constants obtained from the literature had to be decreased in order to fit the data. This is likely because the time constants from the literature were based on experiments performed at room temperature, and the kinetics of $\beta$-adrenergic stimulation are likely to be faster at physiological temperature.

Acceptable fits to the data could be achieved including only $\beta$-adrenergic-mediated phosphorylation of the LCC in the model; including $\beta$-adrenergic PLB phosphorylation alone produced a poor fit with an scvrmse (defined in Eq. 25) value of 1.9241 versus 0.6941 for the fits of Figs. 5 and 6; the associated AIC values (defined in Eq. 27) are 72.6094 and 57.1372 , respectively, corresponding to a relative probability of 0.0004 of the model with PLB phosphorylation only minimizing the information loss compared to the model with LCC phosphorylation only. (See Supporting Material for additional fits.) Interestingly, the quality of the fit is not improved significantly by inclusion of $\beta$-adrenergic PLB phosphorylation in addition to LCC phosphorylation; fits including both $\beta$-adrenergicmediated PLB and LCC phosphorylation yielded an scvrmse value of 0.7148 and an AIC value of 60.9983 , which corresponds to a relative probability of 0.1451 of the model with both LCC and PLB phosphorylation minimizing information loss compared to the one with LCC phosphorylation only. This is consistent with the hypothesis that the major inotropic effect of $\beta$-adrenergic agonists is due to increased $\mathrm{Ca}^{2+}$ influx through the LCC but inconsistent with the hypothesis that faster $\mathrm{Ca}^{2+}$ sequestration into the $\mathrm{SR}$ by inotropes requires upregulation of SERCA via disinhibition of PLB.

Neither CaMKII-mediated phosphorylation of the LCC nor of PLB was required to achieve good fits to the data. (The fits shown in Figs. 5 and 6 were obtained setting $\varphi_{\mathrm{lcc}, \text { CaMKII }}$ and

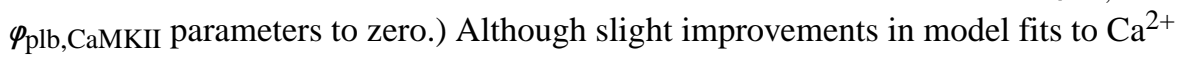
transient amplitude data were achieved by including an additional CaMKII phosphorylation 
pathway, there was no visible difference in the fit of other components of the data and only a small quantitative improvement (scvrmse of 0.6583 for CaMKII \& $\beta A R$ LCC and PLB phosphorylation versus 0.6941 for $\beta$ AR LCC phosphorylation only). Moreover, this small improvement likely represents an upper bound as CaMKII phosphorylation under each experimental condition was allowed as a freely adjustable parameter rather than a variable associated with a kinetic model. The AIC values associated with the two models are 84.8345 for the model including CaMKII LCC and PLB phosphorylation versus 57.1372 for the model including $\beta$ AR LCC phosphorylation only, corresponding to a relative probability of $<0.0001$ of the model including CaMKII minimizing information loss compared to that without. Thus, the small improvement in model fit that might be achievable by inclusion of CaMKII dynamics is insufficient to justify the increased complexity that would be required of the model. A summary of model statistics for each case tested is given in Table 2.

\section{Discussion}

The model developed here represents the first local-control model of $\mathrm{Ca}^{2+}$ dynamics to be parameterized to a self-consistent dataset obtained under physiologically relevant conditions in rat ventricular myocytes. The model updates the Hinch model of $\mathrm{Ca}^{2+}$ dynamics in rat to include $\beta$-adrenergic-mediated regulation of LCC current and SERCA flux. We have also considered the effects of CaMKII regulation on LCC current and SERCA flux, but show that these effects are not necessary to explain the data of Dibb et al. [7]. In addition to providing a physiologically relevant model that can be used to study cardiac function in a variety of contexts, here we have used the model as a tool to examine the relative importance of a variety of mechanisms hypothesized to play a role in frequency- and inotrope-dependent effects on the calcium transient in rats observed under physiologically relevant conditions.

We find that $\beta$-adrenergic-mediated phosphorylation of the LCC but not of PLB is required to explain the increased diastolic $\left[\mathrm{Ca}^{2+}\right]_{\mathrm{i}}$, calcium transient amplitude, and $\mathrm{SR} \mathrm{Ca}^{2+}$ content associated with isoprenaline stimulation. This suggests that increased LCC current plays a more important role than upregulation of SERCA in the inotropic effect of $\beta$-adrenergic stimulation. It is interesting to point out that the data of Dibb et al. [7] show little lusitropic effect of $\beta$-adrenergic stimulation. The primary effect of $\beta$-adrenergic-mediated upregulation of SERCA is thought to be a faster decay of the calcium transient along with decreased diastolic $\left[\mathrm{Ca}^{2+}\right]_{\mathrm{i}}[34]$. However, the data of Dibb et al. show very little acceleration in the rate of calcium transient decay and an increased diastolic $\left[\mathrm{Ca}^{2+}\right]_{\mathrm{i}}$ with isoprenaline stimulation. Thus, these data suggest that the primary mechanism associated with $\beta$ adrenergic-mediated increase in contractility appears to be via the inotropic effects of increased SR $\mathrm{Ca}^{2+}$ content and increased LCC influx. It is also interesting to point out that the concentration of isoprenaline used in the Dibb study is not saturating; rather it lies roughly around the $\mathrm{K}_{\mathrm{m}}$ associated with the isoprenaline dose-reponse curve of LCC current shown in Fig. 2. Simulations (not shown) at a higher isoprenaline dose show that both calcium transient amplitude and diastolic $\left[\mathrm{Ca}^{2+}\right]_{\mathrm{i}}$ become larger. Thus, although the calcium transient amplitude becomes larger, it is possible that too much $\beta$-adrenergic stimulation can cause a drop-off in contractility due to inhibited relaxation of the sarcomere. 
Perhaps the most surprising finding of the current study is that CaMKII effects are not required to capture the frequency dependent changes in $\left[\mathrm{Ca}^{2+}\right]_{\mathrm{i}}$ or $\mathrm{SR} \mathrm{Ca}^{2+}$ observed in the data of Dibb et al. [7]. One attractive and widely postulated hypothesis regarding the frequency-dependent acceleration in the rate of $\left[\mathrm{Ca}^{2+}\right]_{i}$ decay is an increased rate of $\mathrm{Ca}^{2+}$ uptake by SERCA mediated by CaMKII-mediated phosphorylation (either of PLB or of SERCA directly). However, the fits shown in Figs. 5 and 6 are able to explain both the frequency-dependent acceleration in the rate of $\left[\mathrm{Ca}^{2+}\right]_{\mathrm{i}}$ decay and the frequency-dependent increase in $\mathrm{SR} \mathrm{Ca}^{2+}$ content without any frequency-dependent changes in the SERCA model. Thus, the changes in the rate of decay of $\left[\mathrm{Ca}^{2+}\right]_{i}$ in the model are a direct property of the many complex nonlinear interactions between the various components in the model.

SERCA uptake is increased directly with frequency because $\left[\mathrm{Ca}^{2+}\right]_{\mathrm{i}}$ increases with frequency (SERCA pumps faster as $\left[\mathrm{Ca}^{2+}\right]_{\mathrm{i}}$ increases); PMCA flux is also increased for the same reason. The cause of the increased $\left[\mathrm{Ca}^{2+}\right]_{\mathrm{i}}$ with frequency is a combination of increased sarcolemmal influx per unit time along with nonlinear saturating effects of cellular buffering power. (A figure showing $\mathrm{Ca}^{2+}$ fluxes and buffering power versus heart phase (time normalized to heart period) under each experimental condition is shown in the Supporting Material).

In addition, a popular hypothesis regarding the mechanism of frequency-dependent facilitation of the LCC is CaMKII-mediated phosphorylation of the LCC [21]. However, frequency-dependent facilitation of the LCC is not observed in the data of Dibb et al. [7]. Although it could be argued that the mechanism responsible for the biphasic increase and then decrease in $\mathrm{Ca}^{2+}$ transient amplitude with frequency observed in the data is an initial increase due to CaMKII-mediated LCC facilitation which is overcome by LCC inactivation at higher frequencies, including CaMKII-mediated facilitation only marginally improved the fit for the control case, and such a pattern was simulated even without CaMKII effects in the isoprenaline case. Thus, as with the frequency-dependent acceleration of $\left[\mathrm{Ca}^{2+}\right]_{\mathrm{i}}$ decay, the simpler explanation is that this pattern is a result of a complex interplay between transport kinetics, $\left[\mathrm{Ca}^{2+}\right]_{\mathrm{i}}$, and $\mathrm{SR} \mathrm{Ca}^{2+}$ content. Frequency dependent properties of $\mathrm{Ca}^{2+}$ emerge from this relatively simple model without the requirement of additional complexity in the form of CaMKII-mediated regulation of the LCC or of SERCA.

It is important to clarify however that the fact that we were able to achieve satisfactory fits to the dataset of Dibb et al. [7] without the inclusion of CaMKII effects does not mean that CaMKII cannot play a role in modulating $\mathrm{Ca}^{2+}$ dynamics. It may be that CaMKII is functionally unimportant or remains relatively quiescent under the specific set of physiological conditions examined in the Dibb study using isolated myocytes from healthy rats; this situation may change in a different experimental preparation or under a specific disease state. (In general, observations at the molecular/single channel level cannot be expected to generalize as we integrate up to the cell, tissue, and organ level due to the influence of an increasing number of interacting (confounding) pathways at higher levels of organization.) It may also be that the dataset was simply not rich enough to unveil the subtleties of CaMKII signaling and fully challenge the model. For example, in this dataset, diastolic $\mathrm{Ca}^{2+}$ increased with frequency providing a simple explanation for the increased SERCA flux and observed increase in SR $\mathrm{Ca}^{2+}$ content without the need to invoke a CaMKII-mediated mechanism. However, had the data shown a decrease in diastolic $\mathrm{Ca}^{2+}$ 
with frequency, it would have been difficult to explain the increase in $\mathrm{SR} \mathrm{Ca}^{2+}$ content without including CaMKII-mediated effects on SERCA. In addition, CaMKII and $\beta$ adrenergic pathways are known to exhibit synergism, and the dataset of Dibb et al. included only two different levels of isoprenaline (none and $30 \mathrm{nM}$ ). It is possible that CaMKII activation is saturated at the $30 \mathrm{nM}$ dose or quiescent at this dose, in which case the effects of CaMKII would be masked at this dose and unveiled at smaller or larger doses, respectively. The dataset of Dibb et al. [7] was chosen for the present analysis as it provided the best available description of $\mathrm{Ca}^{2+}$ dynamics (including $\mathrm{Ca}^{2+}$ transients, SR content, action potentials, etc.) under physiologically meaningful conditions (temperature, frequency) to include $\beta$-adrenergic stimulation, but including only a single dose of isoprenaline is a limitation. This highlights the need for richer self-consistent datasets under physiologically relevant conditions which would allow computational modeling approaches like that described here to better delineate the specific conditions under which specific signaling pathways become important.

Finally, although we did not consider phosphorylation of RyR in the present study, the model was able to provide acceptable fits to the data of Dibb et al. without including such a mechanism. However, since RyR effects were not included in our analysis, we are unable to make any conclusions regarding the necessity or relative importance of $\beta$-adrenergic or CaMKII-mediated phosphorylation of the RyR in explaining inotrope- or frequencydependence of the data. In conclusion, the model reveals: 1) that $\beta$-adrenergic-mediated phosphorylation of the LCC (and not of PLB) is sufficient to explain the inotropedependence; and 2) that CaMKII-mediated regulation of neither the LCC nor of PLB is required to explain the frequency-dependence of $\mathrm{Ca}^{2+}$ dynamics in the dataset of Dibb et al. [7] obtained from rat ventricular myocytes at physiological temperature and pacing frequencies. Rather, the frequency dependent effects are simply the result of nonlinear interactions between model components.

\section{Supplementary Material}

Refer to Web version on PubMed Central for supplementary material.

\section{Acknowledgments}

This work is supported by the National Institutes of Health (NIH) under Grant No. P50-GM094503. In addition, Scott M. Bugenhagen is a member of the Medical Scientist Training Program at MCW, which is partially supported by a training grant from NIGMS T32-GM080202.

\section{References}

1. Janssen PM, Stull LB, Marban E. Myofilament properties comprise the rate-limiting step for cardiac relaxation at body temperature in the rat. Am J Physiol Heart Circ Physiol. 2002; 282:H499-507. [PubMed: 11788397]

2. Antoons G, Mubagwa K, Nevelsteen I, Sipido KR. Mechanisms underlying the frequency dependence of contraction and $\mathrm{Ca} 2+$ transients in mouse ventricular myocytes. J Physiol. 2002; 15:889-98. [PubMed: 12231646]

3. Bouchard RA, Bose D. Analysis of the interval-force relationship in rat and canine ventricular myocardium. Am J Physiol Heart Circ Physiol. 1989; 257:H2036-47. 
4. Maier LS, Bers DM, Pieske B. Differences in Ca2+ handling and sarcoplasmic reticulum Ca2+ content in isolated rat and rabbit myocardium. J Mol Cell Cardiol. 2000; 32:2249-58. [PubMed: 11113000]

5. Layland J, Kentish JC. Positive force- and [Ca2+]i-frequency relationships in rat ventricular trabeculae at physiological frequencies. Am J Physiol Heart Circ Physiol. 1999; 276:H9-18.

6. Kassiri Z, Myers R, Kaprielian R, Banijamali HS, Backx PH. Rate-dependent changes of twitch force duration in rat cardiac trabeculae: a property of the contractile system. J Physiol. 2000; 524:221-31. [PubMed: 10747194]

7. Dibb KM, Eisner DA, Trafford AW. Regulation of systolic [Ca2+]i and cellular $\mathrm{Ca} 2+$ flux balance in rat ventricular myocytes by SR Ca2+, L-type Ca2+ current and diastolic [Ca2+]i. J Physiol. 2007; 585(Pt 2):579-92. [PubMed: 17932152]

8. Beard DA, Kushmerick MJ. Strong Inference for Systems Biology. PLoS Comput Biol. 2009; 5:e1000459. [PubMed: 19714210]

9. Jafri MS, Rice JJ, Winslow RL. Cardiac Ca2+ dynamics: the roles of ryanodine receptor adaptation and sarcoplasmic reticulum load. Biophys J. 1998; 74:1149-68. [PubMed: 9512016]

10. Iyer V, Mazhari R, Winslow RL. A computational model of the human left-ventricular epicardial myocyte. Biophys J. 2004; 87:1507-25. [PubMed: 15345532]

11. Ten Tusscher KH, Noble D, Noble PJ, Panfilov AV. A model for human ventricular tissue. Am J Physiol Heart Circ Physiol. 2004; 286:H1573-89. [PubMed: 14656705]

12. Shannon TR, Wang F, Puglisi J, Weber C, Bers DB. A mathematical treatment of integrated Ca dynamics within the ventricular myocyte. Biophys J. 2004; 87:3351-71. [PubMed: 15347581]

13. Hinch R, Greenstein JL, Tanskanen AJ, Xu L, Winslow RL. A simplified local control model of calcium-induced calcium release in cardiac ventricular myocytes. Biophys J. 2004; 87:3723-36. [PubMed: 15465866]

14. Niederer SA, Fink M, Noble D, Smith NP. A meta-analysis of cardiac electrophysiology computational models. Exp Physiol. 2009; 94:486-95. [PubMed: 19139063]

15. Li L, Niederer SA, Idigo W, Zhang YY, Swietach P, Casadei B, Smith NP. A mathematical model of the murine ventricular myocyte: a data-driven biophysically based approach applied to mice overexpressing the canine NCX isoform. Am J Physiol Heart Circ Physiol. 2010; 299:H1045-63. [PubMed: 20656884]

16. Bondarenko VE, Szigeti GP, Bett GC, Kim SJ, Rasmusson RL. Computer model of action potential of mouse ventricular myocytes. Am J Physiol Heart Circ Physiol. 2004; 287:H1378-403. [PubMed: 15142845]

17. Beard DA, Neal ML, Tabesh-Saleki N, Thompson CT, Bassingthwaighte JB, Shimoyama M, Carlson BE. Multiscale modeling and data integration in the Virtual Physiological Rat Project. Ann Biomed Eng. 2012; 40:2365-78. [PubMed: 22805979]

18. Endoh M. Force-frequency relationship in intact mammalian ventricular myocardium: physiological and pathophysiological relevance. Eur J Pharmacol. 2004; 500:73-86. [PubMed: 15464022]

19. De Koninck P, Schulman H. Sensitivity of CaM kinase II to the frequency of $\mathrm{Ca} 2+$ oscillations. Science. 1998; 279:227-30. [PubMed: 9422695]

20. Hudmon A, Schulman H, Kim J, Maltez JM, Tsien RW, Pitt GS. CaMKII tethers to L-type Ca2+ channels, establishing a local and dedicated integrator of $\mathrm{Ca} 2+$ signals for facilitation. J Cell Biol. 2005; 171:537-47. [PubMed: 16275756]

21. Maier LS, Bers DM. Calcium, calmodulin, and calcium-calmodulin kinase II: heartbeat to heartbeat and beyond. J Mol Cell Cardiol. 2002; 34:919-39. [PubMed: 12234763]

22. Guo T, Zhang T, Mestril R, Bers DM. Ca2+/calmodulin-dependent protein kinase II phosphorylation of ryanodine receptor does affect calcium sparks in mouse ventricular myocytes. Circ Res. 2006; 99:398-406. [PubMed: 16840718]

23. Yang D, Zhu WZ, Xiao B, Brochet DXP, Chen SRW, Lakatta EG, Xiao RP, Cheng H. Ca2+/ calmodulin kinase II-dependent phosphorylation of ryanodine receptors suppresses $\mathrm{Ca} 2+$ sparks and Ca2+ waves in cardiac myocytes. Circ Res. 2007; 100:399-407. [PubMed: 17234969] 
24. Hashambhoy YL, Greenstein HL, Winslow RL. Role of CaMKII in RyR leak, EC coupling and action potential duration: a computational model. J Mol Cell Cardiol. 2010; 49:617-24. [PubMed: 20655925]

25. Guo J, Duff HJ. Calmodulin kinase II accelerates L-type Ca2+ current recovery from inactivation and compensates for the direct inhibitory effect of $[\mathrm{Ca} 2+] \mathrm{i}$ in rat ventricular myocytes. J Physiol. 2006; 15:509-18. [PubMed: 16627565]

26. Blaich A, Welling A, Fischer S, Wegener JW, Kostner K, Hofmann F, Moosmang S. Facilitation of murine cardiac L-type $\mathrm{Ca}(\mathrm{v}) 1.2$ channel is modulated by calmodulin kinase II-dependent phosphorylation of S1512 and S1570. Proc Natl Acad Sci USA. 2010; 107:10285-9. [PubMed: 20479240]

27. Bassani RA, Mattiazzi A, Bers DM. CaMKII is responsible for activity-dependent acceleration of relaxation in rat ventricular myocytes. Am J Physiol. 1995; 268:H703-12. [PubMed: 7864197]

28. Li L, Chu G, Kranias EG, Bers DB. Cardiac myocyte calcium transport in phospholamban knockout mouse: relaxation and endogenous CaMKII effects. Am J Physiol. 1998; 274:H1335-47. [PubMed: 9575939]

29. DeSantiago J, Maier LS, Bers DB. Frequency-dependent acceleration of relaxation in the heart depends on CaMKII, but not phospholamban. J Mol Cell Cardiol. 2002; 34:975-84. [PubMed: 12234767]

30. Hagemann D, Kuschel M, Kuramochi T, Zhu W, Cheng H, Xiao RP. Frequency-encoding Thr17 phospholamban phosphorylation is independent of Ser16 phosphorylation in cardiac myocytes. $\mathbf{J}$ Biol Chem. 2000; 275:22532-36. [PubMed: 10825152]

31. Bluhm WF, Kranias EG, Dillman WH, Meyer M. Phospholamban: a major determinant of the cardiac force-frequency relationship. Am J Physiol Heart Circ Physiol. 2000; 278:H249-55. [PubMed: 10644605]

32. Hussain M, Drago GA, Colyer J, Orchard CH. Rate-dependent abbreviation of $\mathrm{Ca} 2+$ transient in rat heart is independent of phospholamban phosphorylation. Am J Physiol. 1997; 273:H695-706. [PubMed: 9277486]

33. Valverde CA, Mundina-Wilenmann C, Said M, Ferrero P, Vittone L, Salas M, Palomeque J, Petroff MV, Mattiazzi A. Frequency-dependent acceleration of relaxation in mammalian heart: a property not relying on phospholamban and SERCA2a phosphorylation. J Physiol. 2005; 562:801-13. [PubMed: 15528241]

34. Bers DM. Cardiac excitation-contraction coupling. Nature. 2002; 415:198-205. [PubMed: 11805843]

35. Saucerman JJ, Brunton LL, Michailova AP, McCulloch AD. Modeling beta-adrenergic control of cardiac myocyte contractility in silico. J Biol Chem. 2003; 278:47997-8003. [PubMed: 12972422]

36. Saraiva RM, Chedid NG, Quintero HCC, Diaz GLE, Masuda MO. Impaired beta-adrenergic response and decreased L-type calcium current of hypertrophied left ventricular myocytes in postinfarction heart failure. Braz J Med Biol Res. 2003; 36:635-48. [PubMed: 12715084]

37. Yatani A, Brown AM. Rapid beta-adrenergic modulation of cardiac calcium channel currents by a fast G protein pathway. Science. 1989; 245:71-4. [PubMed: 2544999]

38. Lindemann JP, Jones LR, Hathaway DR, Henry BG, Watanabe AM. Beta-adrenergic stimulation of phospholamban phosphorylation and $\mathrm{Ca} 2+-\mathrm{ATPase}$ activity in guinea pig ventricles. J Biol Chem. 1983; 258:464-71. [PubMed: 6217205]

39. Li L, DeSantiago J, Chu G, Kranias EG, Bers DM. Phosphorylation of phospholamban and troponin I in beta-adrenergic-induced acceleration of cardiac relaxation. Am J Physiol. 2000; 278:H769-H779.

40. Dupont G, Houart G, De Koninck P. Sensitivity of CaM kinase II to the frequency of Ca2+ oscillations: a simple model. Cell Calcium. 2003; 34:485-97. [PubMed: 14572807]

41. Lucic V, Greif GJ, Kennedy MB. Detailed state model of CaMKII activation and autophosphorylation. Eur Biophys J. 2008; 38:83-98. [PubMed: 18769913]

42. Saucerman JJ, Bers DM. Calmodulin mediates differential sensitivity of CaMKII and calcineurin to local Ca2+ in cardiac myocytes. Biophys J. 2008; 95:4597-612. [PubMed: 18689454] 
43. Chiba H, Schneider NS, Matsuoka S, Noma A. A simulation study on the activation of cardiac CaMKII delta-isoform and its regulation by phosphatases. Biophys J. 2008; 95:2139-49. [PubMed: 18502812]

44. Yue DT, Herzig S, Marban E. Beta-adrenergic stimulation of calcium channels occurs by potentiation of high-activity gating modes. Proc Natl Acad Sci USA. 1990; 87:753-7. [PubMed: 1689051]

45. Dzhura I, Wu Y, Colbran RJ, Balser JR, Anderson ME. Calmodulin kinase determines calciumdependent facilitation of L-type calcium channels. Nat Cell Biol. 2000; 2:173-7. [PubMed: 10707089]

46. Sun AY, Pitt GS. Pinning down the CaMKII targets in the L-type Ca2+ channel: an essential step in defining CaMKII regulation. Heart Rhythm. 2011; 8:631-633. [PubMed: 20933100]

47. Simmerman HKB, Jones LR. Phospholamban: protein structure, mechanism of action, and role in cardiac function. Physiol Rev. 1998; 78:921-47. [PubMed: 9790566]

48. Hagemann D, Xiao RP. Dual site phospholamban phosphorylation and its physiological relevance in the heart. Trends Cardiovasc Med. 2002; 12:51-6. [PubMed: 11852250]

49. Trafford AW, Diaz ME, Eisner DA. A novel, rapid and reversible method to measure Ca buffering and time-course of total sarcoplasmic reticulum $\mathrm{Ca}$ content in cardiac ventricular myocytes. Pflugers Arch. 1999; 437:501-3. [PubMed: 9914410]

50. Page E, McCallister LP, Power B. Stereological measurements of cardiac ultrastructures implicated in excitation-contraction coupling. Proc Natl Acad Sci USA. 1971; 68:1465-1466. [PubMed: 5283936]

51. Pandit SV, Clark RB, Giles WR, Demir SS. A mathematical model of action potential heterogeneity in adult rat left ventricular myocytes. Biophys J. 2001; 81:3029-51. [PubMed: 11720973]

52. Pandit SV, Giles WR, Demir SS. A mathematical model of the electrophysiological alterations in rat ventricular myocytes in type-I diabetes. Biophys J. 2003; 84:832-841. [PubMed: 12547767]

53. Varro A, Negretti N, Hester SB, Eisner DA. An estimate of the calcium content of the sarcoplasmic reticulum in rat ventricular myocytes. Pflugers Arch. 1993; 423:158-60. [PubMed: 8488088]

54. Charbonneau, P.; Knapp, B. NCAR Technical Note TN-450+IA. National Center for Atmospheric Research; Boulder: 1995. A user's guide to PIKAIA 1.0.

55. Walden AP, Dibb KM, Trafford AW. Differences in intracellular calcium homeostasis between atrial and ventricular myocytes. J Mol Cell Cardiol. 2009; 46:463-73. [PubMed: 19059414]

56. Ito K, Yan X, Tajima M, Su Z, Barry WH, Lorell BH. Contractile reserve and intracellular calcium regulation in mouse myocytes from normal and hypertrophied failing hearts. Circ Res. 2000; 87:588-95. [PubMed: 11009564]

57. Luo CH, Rudy Y. A dynamic model of the cardiac ventricular action potential. I. Simulations of ionic currents and concentration changes. Circ Res. 1994; 74:1071-96. [PubMed: 7514509]

58. Dobrev D, Wehrens XH. Role of RyR2 phosphorylation in heart failure and arrhythmias: Controversies around ryanodine receptor phosphorylation in cardiac disease. Circ Res. 2014; 114:1311-9. [PubMed: 24723656]

59. Camors E, Valdivia HH. CaMKII regulation of cardiac ryanodine receptors and inositol triphosphate receptors. Front Pharmacol. 2014; 5:101. [PubMed: 24847270]

60. Kushnir A, Shan J, Betzenhauser MJ, Reiken S, Marks AR. Role of CaMKIIdelta phosphorylation of the cardiac ryanodine receptor in the force frequency relationship and heart failure. Proc Natl Acad Sci USA. 2010; 107:10274-9. [PubMed: 20479242]

61. Wu Y, Luczak ED, Lee EJ, Hidalgo C, Yang J, Gao Z, Li J, Wehrens X, Granzier H, Anderson ME. CaMKI effects on inotropic but not lusitropic force-frequency responses require phospholamban. J Mol Cell Cardiol. 2012; 53:429-436. [PubMed: 22796260]

62. Frace AM, Mery PF, Fischmeister R, Hartzell HC. Rate-limiting steps in the beta-adrenergic stimulation of cardiac calcium current. J Gen Physiol. 1993; 101:337-53. [PubMed: 8386216]

63. Carmeliet E. Intracellular $\mathrm{Ca} 2+$ concentration and rate adaptation of the cardiac action potential. Cell Calcium. 2004; 35:557-73. [PubMed: 15110146] 
64. Rocchetti M, Freli V, Perego V, Altomare C, Mostacciuolo G, Zaza A. Rate dependency of betaadrenergic modulation of repolarizing currents in the guinea-pig ventricle. J Physiol. 2006; 574:183-93. [PubMed: 16484299]

65. Scamps F. Characterization of a beta-adrenergically inhibited $\mathrm{K}+$ current in rat cardiac ventricular cells. J Physiol. 1996; 491:81-97. [PubMed: 9011624]

66. Patterson E, Lazzara R, Szabo B, Liu H, Tang D, Li YH, Scherlag BJ, Po SS. J Am Coll Cardiol. 2006; 47:1196-206. [PubMed: 16545652] 


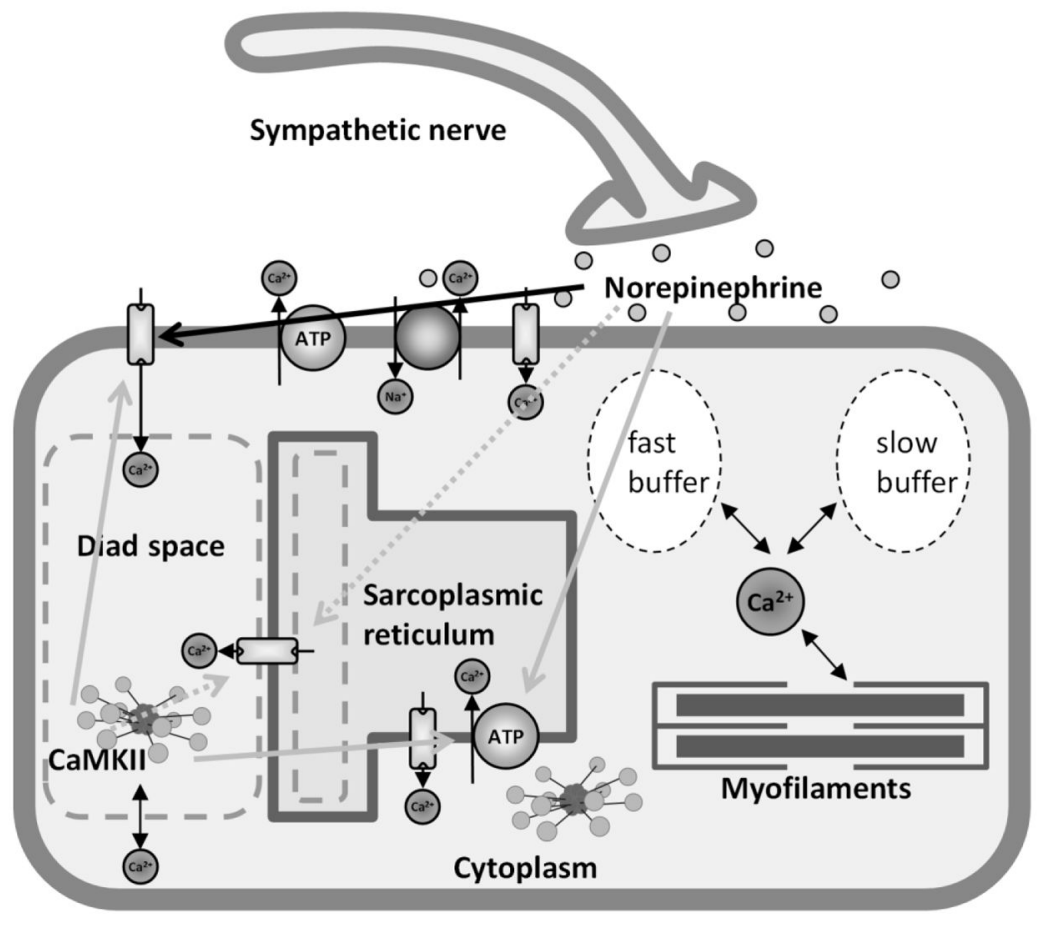

Figure 1. $\mathrm{Ca}^{2+}$ dynamics model components

The computational model of $\mathrm{Ca}^{2+}$ dynamics used in this study updates the Hinch framework [13] to include CaMKII and $\beta$-adrenergic signaling pathways. The black line in the diagram indicates a dependency that was required in order to fit the data of Dibb et al. [7], whereas the gray lines indicate dependencies that are known to exist but found to be unnecessary to fit the data of Dibb et al. [7] (solid lines are dependencies that were actually tested, and dotted lines indicate dependencies that were not considered in the model). 


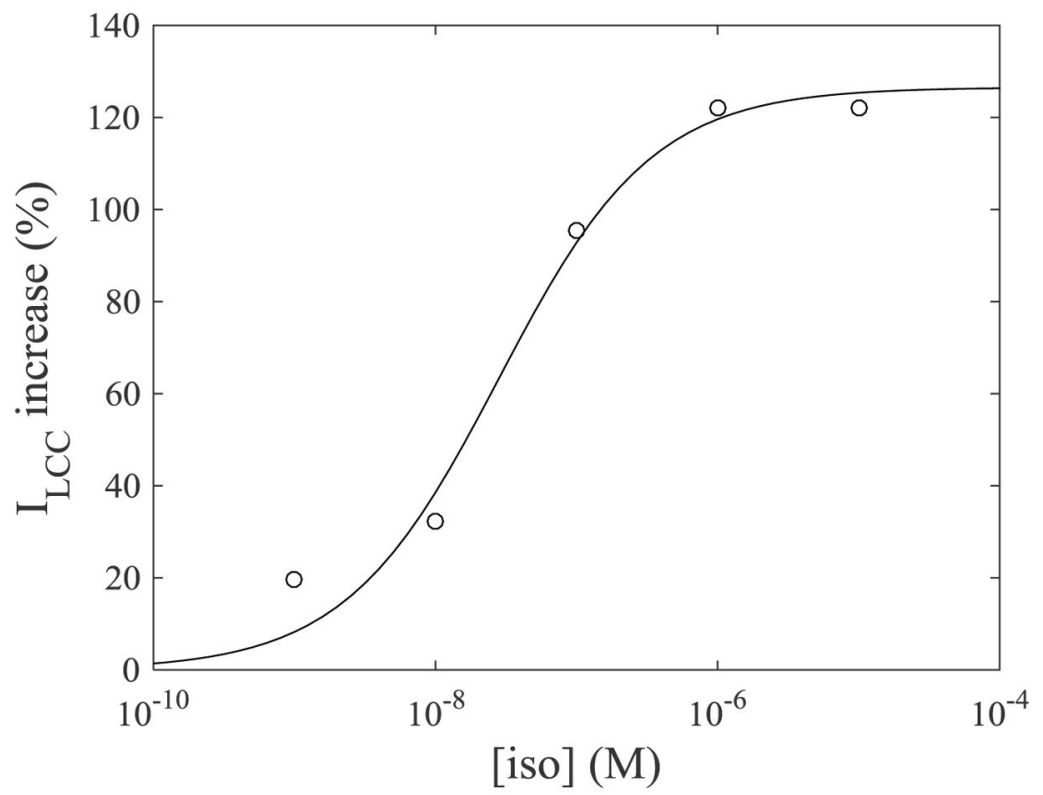

Figure 2. Steady-state isoprenaline dose response of $\mathbf{I}_{\mathbf{L C C}}$

Data (circles) are from Saraiva et al. [36] and represent the percentage increase in LCC current from baseline following a dose of isoprenaline. It is assumed here that $\mathrm{I}_{\mathrm{LCC}}$ increase is linearly related to LCC phosphorylation fraction. The fits (solid line) to the data using Eq. 1 are used to estimate the half-response concentration and Hill coefficient parameters associated with isoprenaline-mediated LCC phosphorylation. 
a)

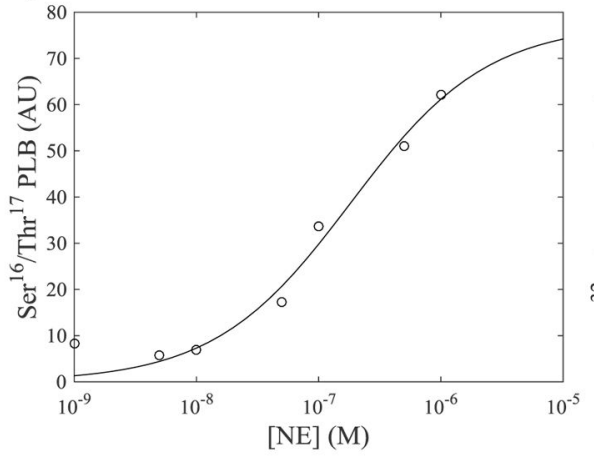

b)

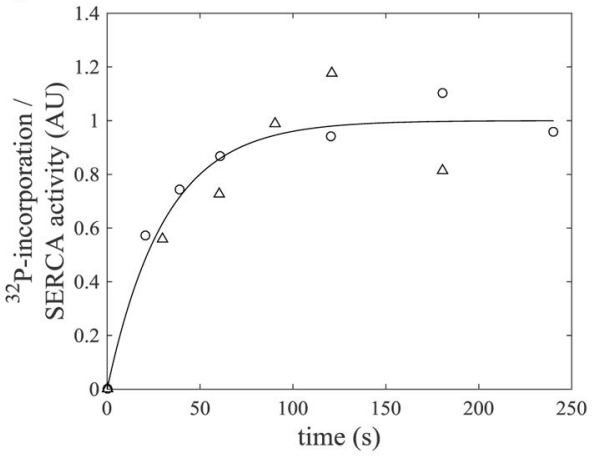

Figure 3. Steady-state and dynamic isoprenaline response of PLB phosphorylation A) Steady-state PLB phosphorylation data (circles) of Hagemann et al. [30] at different isoprenaline doses are shown along with model fits (solid line) to the data using Eq. 3 which are used to estimate the half-response concentration and Hill coefficient parameters associated with isoprenaline-mediated PLB phosphorylation. The phosphorylation data

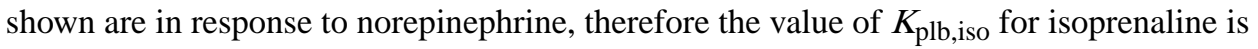
obtained by dividing the fit by 10 to account for the tenfold higher affinity of isoprenaline compared to norepinephrine. B) Dynamic isoprenaline-mediated PLB phosphorylation data (triangles) of Li et al. [39] are plotted alongside data (circles) of dynamic isoprenalinemediated changes in SERCA activity from Lindemann et al. [38], illustrating the direct correspondence between PLB phosphorylation and SERCA activity. (The two datasets were normalized to their steady-state value in order to more clearly show their correlation in time.) The data are well fit (solid line) by the first-order process given by Eq. 4. 
a)

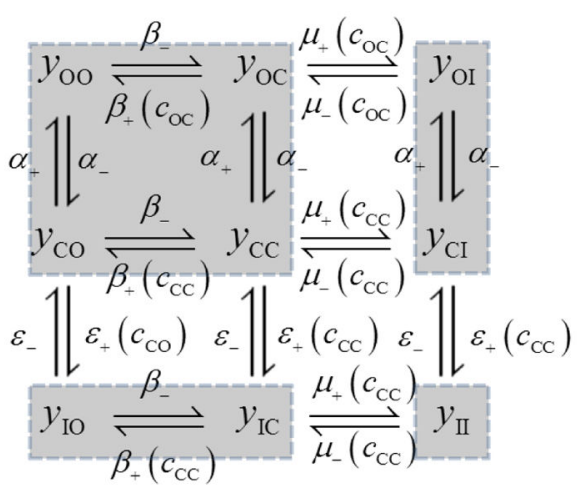

b)

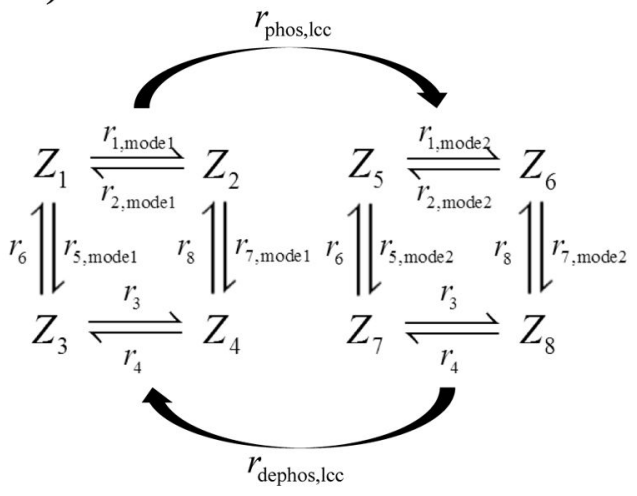

Figure 4. Calcium release unit model

The calcium release unit model is adapted from the model of Hinch et al. [13] to include modal gating to account for phosphorylation of LCCs by PKA and CaMKII. A) The ninestate model results from the Cartesian product of the three-state LCC and RyR models, assuming the $\mathrm{CaRU}$ is comprised of one of each. In the diagram, $y_{i, j}$ represents the occupancy probability of a CaRU state in which the LCC is in state $i \in\{\mathrm{O}, \mathrm{C}, \mathrm{I}\}$ and the RyR is in state $j \in\{\mathrm{O}, \mathrm{C}, \mathrm{I}\}$. Similarly, some rate constants are a function of diad space calcium concentration $c_{i, j}$, which is assumed to be a function of CaRU state. B) By assuming inactivation/de-inactivation is slow compared to opening/closing of the channels, the ninestate model is reduced to a four-state model by invoking a rapid equilibrium approximation (states assumed to be in quasi-equilibrium are boxed together in panel $\mathrm{A}$, and $\mathrm{Z}_{1}-\mathrm{Z}_{4}$ represent the aggregate occupancy probability of the corresponding boxes). Here, it is assumed that LCCs operate in one of two modes depending on phosphorylation state, requiring an additional four states $\left(\mathrm{Z}_{5}-\mathrm{Z}_{8}\right)$ in the model. 
a)
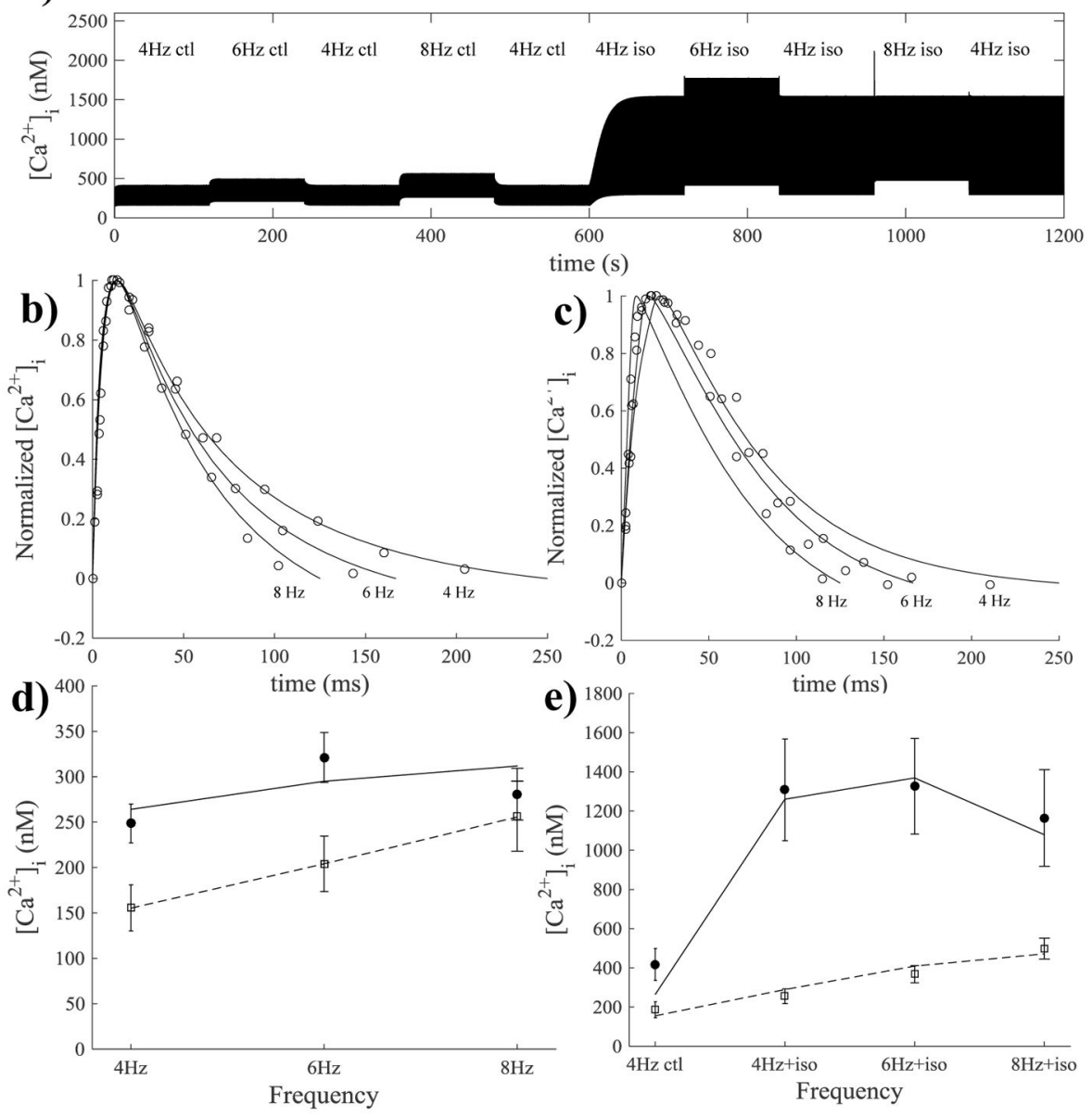

e)

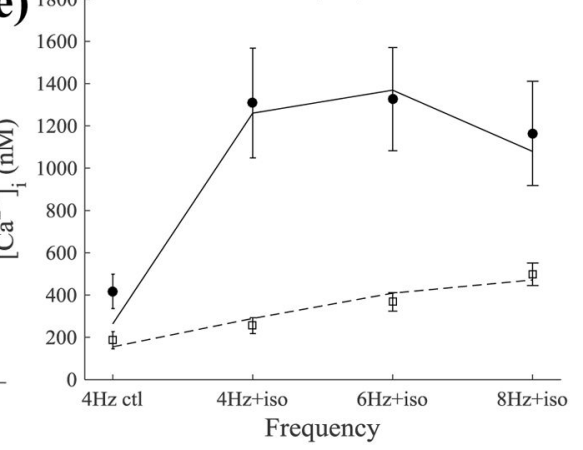

Figure 5. $\mathrm{Ca}^{2+}$ dynamics model fits

The $\mathrm{Ca}^{2+}$ dynamics model is fit to the data of Dibb et al. [7]. Panel A shows a simulation of the experiment performed by Dibb et al. [7], in which cardiac myocytes under current clamp are stimulated at three different frequencies in the absence and presence of isoprenaline.

Each condition is simulated for two minutes before switching pacing frequency. A 30nM dose of isoprenaline is added at time $600 \mathrm{~s}$, resulting in a large increase in $\left[\mathrm{Ca}^{2+}\right]_{\mathrm{i}}$. Panels $\mathrm{B}$ and $\mathrm{C}$ show the simulated (solid line) and experimentally observed (circles) normalized calcium transient corresponding to the final beat of the corresponding two-minute interval in the absence and presence of isoprenaline, respectively. Similarly, panels D and E show simulated (dashed line) and experimentally observed (open squares) diastolic $\left[\mathrm{Ca}^{2+}\right]_{\mathrm{i}}$ along with simulated (solid line) and experimental (solid circles) amplitude of the calcium transient in the absence and presence of isoprenaline, respectively. 

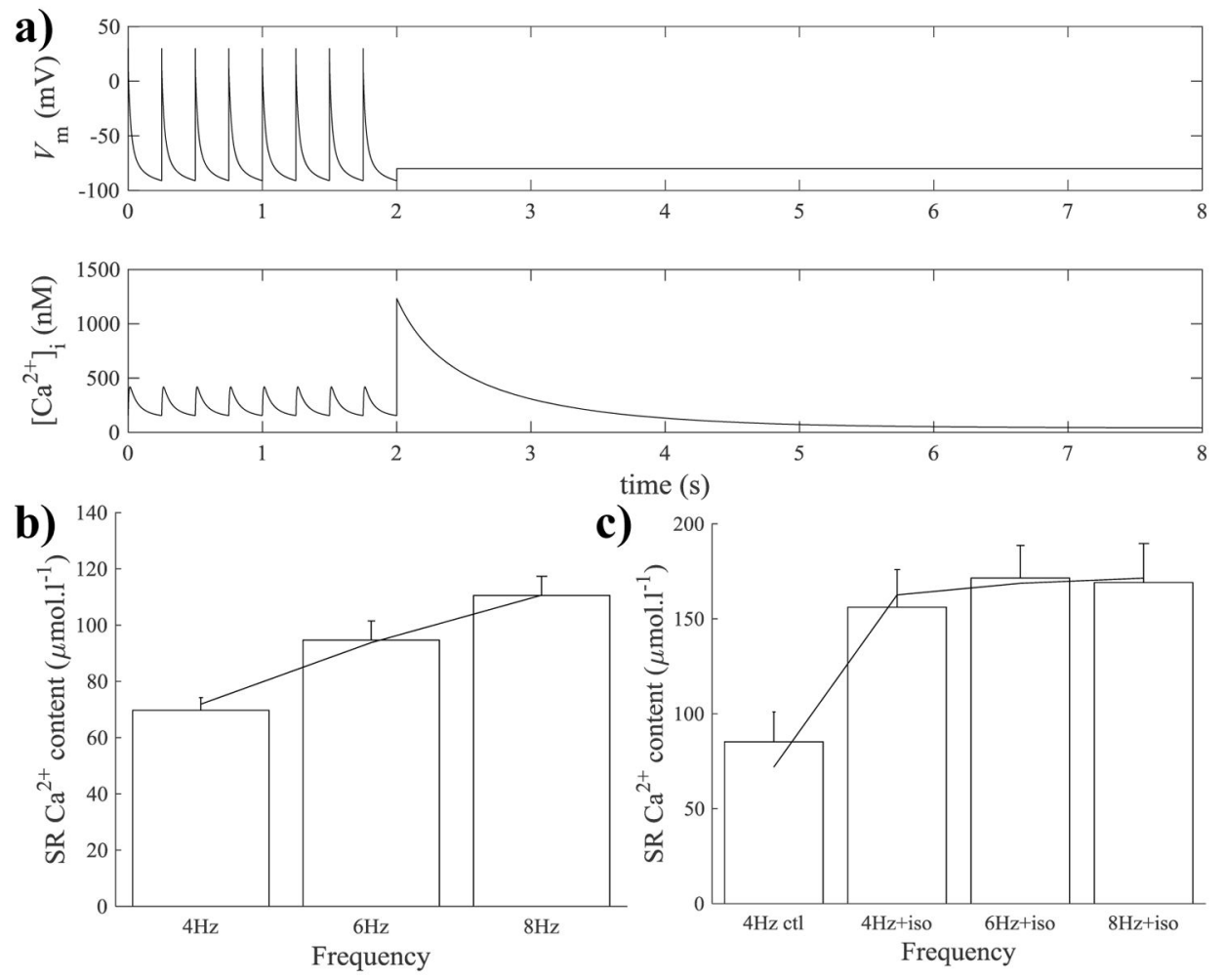

c) 200

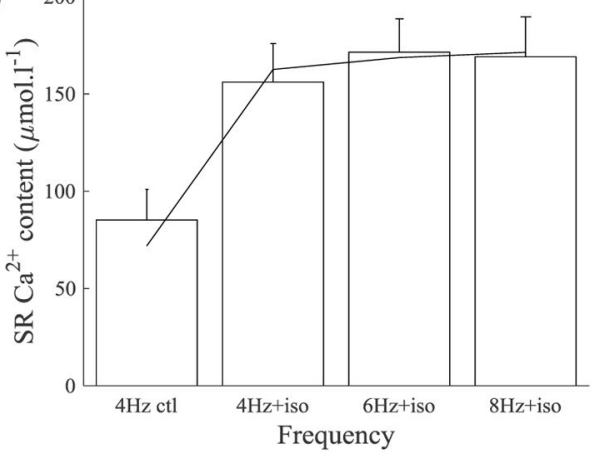

Figure 6. $\mathrm{SR} \mathrm{Ca}^{2+}$ content model fits

The $\mathrm{Ca}^{2+}$ dynamics model is fit to the SR $\mathrm{Ca}^{2+}$ content data of Dibb et al. [7]. Panel A shows a simulation of the experiment performed by Dibb et al. [7], in which cardiac myocytes under current clamp are stimulated at $4 \mathrm{~Hz}$ until a steady-state is reached and then switched to voltage clamp at $-80 \mathrm{mV}$ and given a $10 \mathrm{mM}$ dose of caffeine to discharge SR $\mathrm{Ca}^{2+}$. In the simulation, the effect of caffeine is simulated by increasing the SR leak parameter $10^{4}$-fold at the 2 -second time point. The integrated NCX flux associated with the caffeine-induced $\mathrm{Ca}^{2+}$ transient, corrected to account for non-electrogenic $\mathrm{Ca}^{2+}$ removal according to the method of Varro et al. [53], is taken as an index of $\mathrm{SR} \mathrm{Ca}^{2+}$ content. Experimentally measured (boxes) and simulated (solid lines) $\mathrm{SR} \mathrm{Ca}^{2+}$ content in the absence and presence of isoprenaline is shown in panels $\mathrm{B}$ and $\mathrm{C}$, respectively. 


\section{Table 1}

Parameters, definitions, and units associated with the $\mathrm{Ca}^{2+}$ dynamics model are listed. Parameters designated as "Fitted" are estimated from the data of Dibb et al. [7] shown in Figs. 5 and 6.

\begin{tabular}{|c|c|c|}
\hline Physical constants \& geometry & & Source \\
\hline$C_{\mathrm{m}}=155.4 \mathrm{pF}$ & Membrane capacitance & $(55)$ \\
\hline$V_{\text {tot }}=2.2988 \times 10^{-11} \mathrm{~L}$ & Total cell volume & (55) \\
\hline$F=96.485 \mathrm{C} \mathrm{mmol}^{-1}$ & Faraday constant & Standard value \\
\hline$R=8.3145 \times 10^{-3} \mathrm{~J} \mathrm{mmol}^{-1} \mathrm{~K}^{-1}$ & Universal gas constant & Standard value \\
\hline$T=310.15 \mathrm{~K}$ & Temperature & Experimental cond. \\
\hline$\lambda_{\mathrm{i}}=0.65$ dimensionless & Myoplasmic/total cell volume fraction & (50) \\
\hline$\lambda_{\mathrm{SR}}=0.035$ dimensionless & $\mathrm{SR} /$ total cell volume fraction & $(50)$ \\
\hline$v_{\mathrm{ds}}=253.9459 \mathrm{~s}^{-1}$ & Diadic space collapse rate & Fitted \\
\hline$V_{\mathrm{Icc}}=3.8377 \mathrm{~s}^{-1}$ & LCC release rate & Fitted \\
\hline$V_{\mathrm{ryr}}=4.4955 \times 10^{4} \mathrm{~s}^{-1}$ & RyR release rate & Fitted \\
\hline \multicolumn{3}{|l|}{ Fixed ionic concentrations } \\
\hline$\left[\mathrm{Na}^{+}\right]_{\mathrm{i}}=10 \mathrm{mM}$ & Myoplasmic $\mathrm{Na}^{+}$concentration & (57) \\
\hline$\left[\mathrm{Na}^{+}\right]_{\mathrm{o}}=140 \mathrm{mM}$ & Extracellular $\mathrm{Na}^{+}$concentration & (57) \\
\hline$\left[\mathrm{Ca}^{2+}\right]_{\mathrm{O}}=1.8 \mathrm{mM}$ & Extracellular $\mathrm{Ca}^{2+}$ concentration & (57) \\
\hline [iso] $=0$ or $30 \times 10^{-6} \mathrm{mM}$ & Concentration of isoprenaline in cell bath & Experimental cond. \\
\hline \multicolumn{3}{|l|}{ Buffering } \\
\hline$[\mathrm{B}]_{\mathrm{i}}=0.2366 \mathrm{mM}$ & Intrinsic myoplasmic buffer concentration & Fitted \\
\hline$K_{\mathrm{B}, \mathrm{i}}=0.001 \mathrm{mM}$ & Dissociation constant of myoplasmic buffer & Fitted \\
\hline$[\mathrm{B}]_{\mathrm{SR}}=8.9495 \mathrm{mM}$ & Intrinsic SR buffer concentration & Fitted \\
\hline$K_{\mathrm{B}, \mathrm{SR}}=0.3278 \mathrm{mM}$ & Dissociation constant of SR buffer & Fitted \\
\hline$[\text { fluo }]_{\mathrm{i}}=5 \times 10^{-3} \mathrm{mM}$ & Concentration of fluorophore (Fluo-3 AM) & Experimental cond. \\
\hline$K_{\text {fluo }}=8.64 \times 10^{-4} \mathrm{mM}$ & Dissociation constant of fluorophore (Fluo-3 AM) & (56) \\
\hline \multicolumn{3}{|l|}{$L C C$} \\
\hline$V_{\text {half }}^{\text {lcc }}=-2 \times 10^{-3} \mathrm{~V}$ & Half open potential of LCCs & (13) \\
\hline$\Delta V_{\mathrm{lcc}}=7 \times 10^{-3} \mathrm{~V}$ & Width of opening potential & (13) \\
\hline$k_{\mathrm{open}}^{\mathrm{lcc}}=1 \times 10^{4} \mathrm{~s}^{-1}$ & LCC opening rate & Arbitrarily fast \\
\hline$k_{\text {close }, \text { mode } 1}^{\text {lcc }}=2.5666 \times 10^{4} \mathrm{~s}^{-1}$ & Closing rate of unphosphorylated LCC & Fitted \\
\hline$k_{\text {close }, \text { mode } 2}^{\mathrm{lcc}}=1.8174 \times 10^{3} \mathrm{~s}^{-1}$ & Closing rate of phosphorylated LCC & Fitted \\
\hline$k_{\text {inact,min }}^{\text {lcc }}=89.9178 \mathrm{mM}^{-1} \mathrm{~s}^{-1}$ & Minimum rate of LCC inactivation & Fitted \\
\hline$k_{\text {inact }, \max }^{\text {lcc }}=1.7218 \times 10^{4} \mathrm{mM}^{-1} \mathrm{~s}^{-1}$ & Maximum rate of LCC inactivation & Fitted \\
\hline
\end{tabular}




\begin{tabular}{|c|c|c|}
\hline Physical constants \& geometry & & Source \\
\hline$k_{\text {deinact }, \min }^{\text {lcc }}=0.2201 \mathrm{~s}^{-1}$ & Minimum rate of LCC deinactivation & Fitted \\
\hline$k_{\text {deinact,max }}^{\text {lcc }}=25.0826 \mathrm{~s}^{-1}$ & Maximum rate of LCC deinactivation & Fitted \\
\hline \multicolumn{3}{|l|}{$R y R$} \\
\hline$K_{\mathrm{ryr}}=0.0363 \mathrm{mM}$ & Half activation concentration of RyR & Fitted \\
\hline$k_{\mathrm{open}}^{\mathrm{ryr}}=5.7615 \times 10^{3} \mathrm{~s}^{-1}$ & RyR opening rate & Fitted \\
\hline$k_{\text {close }}^{\mathrm{ryr}}=519.2465 \mathrm{~s}^{-1}$ & RyR closing rate & Fitted \\
\hline$k_{\text {inact, } \min }^{\mathrm{ryr}}=37.1256 \mathrm{~s}^{-1}$ & Minimum rate of RyR inactivation & Fitted \\
\hline$k_{\text {inact, } \max }^{\mathrm{ryr}}=205.3782 \mathrm{~s}^{-1}$ & Maximum rate of RyR inactivation & Fitted \\
\hline$k_{\text {deinact, } \min }^{\mathrm{ryr}}=31.4182 \mathrm{~s}^{-1}$ & Minimum rate of RyR deinactivation & Fitted \\
\hline$k_{\text {deinact,max }}^{\mathrm{ryr}}=1.1077 \times 10^{3} \mathrm{~s}^{-1}$ & Maximum rate of RyR deinactivation & Fitted \\
\hline \multicolumn{3}{|l|}{$S E R C A$} \\
\hline$K_{\text {serca }}=4.6430 \times 10^{-4} \mathrm{mM}$ & Half activation concentration of SERCA & Fitted \\
\hline$J_{\text {serca,max }}=0.9147 \mathrm{mmol} \mathrm{s}^{-1}(\mathrm{~L} \text { cell vol })^{-1}$ & Maximum uptake rate of SERCA & Fitted \\
\hline$\zeta_{\mathrm{plb}}=1$ & Inhibition factor associated with PLB & Assumption \\
\hline \multicolumn{3}{|l|}{$N C X$} \\
\hline$J_{\text {ncx }, 0}=54.3859 \mathrm{mmol} \mathrm{s}^{-1}(\mathrm{~L} \mathrm{cell} \mathrm{vol})^{-1}$ & NCX transport rate & Fitted \\
\hline$K_{\mathrm{ncx}, \mathrm{Na}}=87.5 \mathrm{mM}$ & $\mathrm{Na}^{+}$half saturation concentration of $\mathrm{NCX}$ & $(57)$ \\
\hline$K_{\text {ncx,Ca }}=1.38 \mathrm{mM}$ & $\mathrm{Ca}^{2+}$ half saturation concentration of $\mathrm{NCX}$ & $(57)$ \\
\hline$k_{\text {ncx,sat }}=0.1$ dimensionless & NCX saturation factor & $(57)$ \\
\hline$\eta_{\mathrm{ncx}}=0.35$ dimensionless & Voltage dependence factor of NCX & $(57)$ \\
\hline \multicolumn{3}{|l|}{$P M C A$} \\
\hline$J_{\text {pmca, } \max }=0.0360 \mathrm{mmol} \mathrm{s}^{-1}(\mathrm{~L} \text { cell vol })^{-1}$ & Maximum pump rate of PMCA & Fitted \\
\hline$K_{\mathrm{pmca}}=3.5354 \times 10^{-4} \mathrm{mM}$ & PMCA Half-activation concentration & Fitted \\
\hline \multicolumn{3}{|l|}{ Leak currents } \\
\hline$V_{\text {leak }, \mathrm{sr}}=0.9928 \mathrm{~s}^{-1}$ & SR leak rate & Fitted \\
\hline$g_{\text {leak }, \mathrm{pm}}=0.0176 \mathrm{mmol} \mathrm{V}^{-1} \mathrm{~s}^{-1}(\mathrm{~L} \text { cell vol })^{-1}$ & Sarcolemmal leak conductance & Fitted \\
\hline \multicolumn{3}{|l|}{$\beta$-adrenergic pathway } \\
\hline$\varphi_{\mathrm{lcc}, \text { iso }}^{\max }=0.9861$ dimensionless & Maximum isoprenaline-mediated LCC activation & Fitted \\
\hline$K_{\mathrm{lcc}, \text { iso }}=2.8083 \times 10^{-5} \mathrm{mM}$ & Half concentration of isoprenaline LCC activation & See Fig. 2 \\
\hline$H_{\text {lcc,iso }}=0.7984$ dimensionless & Hill coefficient of isoprenaline LCC activation & See Fig. 2 \\
\hline$\tau_{\mathrm{lcc}, \text { iso }}=12 \mathrm{~s}$ & Time constant of isoprenaline LCC activation & Fitted \\
\hline$\varphi_{\mathrm{plb}, \text { iso }}^{\max }=0$ dimensionless & Max isoprenaline-mediated PLB phosphorylation & Assumption \\
\hline
\end{tabular}




\begin{tabular}{llc}
\hline Physical constants \& geometry & & Source \\
$K_{\mathrm{plb}, \text { iso }}=1.8299 \times 10^{-5} \mathrm{mM}$ & Half concentration of PLB phosphorylat ion & See Fig. 3 \\
$H_{\mathrm{plb}, \text { iso }}=0.7785$ dimensionless & Hill coefficient of PLB phosphorylation & See Fig. 3 \\
$\tau_{\mathrm{plb}, \text { iso }}=10.3383 \mathrm{~s}$ & Time constant of PLB phosphorylation & Fitted \\
CaMKII pathway & & \\
$\varphi_{\mathrm{lcc}, \text { CaMKII }}=0$ & CaMKII-mediated LCC activation & Assumption \\
$\varphi_{\mathrm{plb}, \text { CaMKII }}=0$ & CaMKII-mediated PLB phosphorylation & Assumption \\
\hline
\end{tabular}




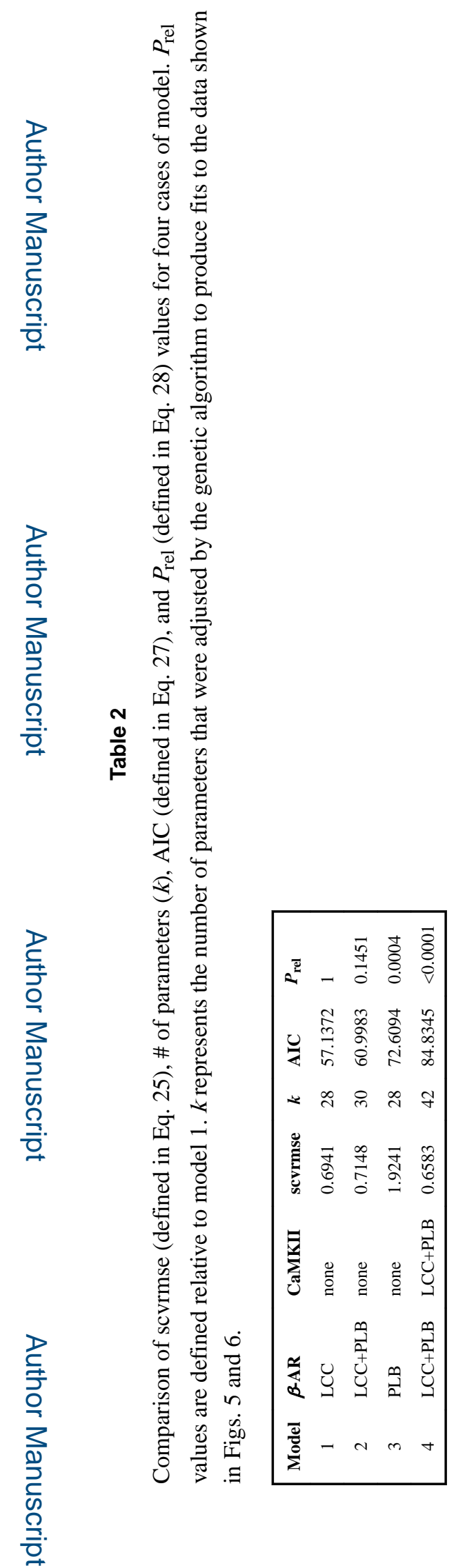

Phys Biol. Author manuscript; available in PMC 2016 October 01. 